\title{
Coskewness Risk Decomposition, Covariation Risk, and Intertemporal Asset Pricing
}

\author{
Petko S. Kalev, Konark Saxena, and Leon Zolotoy*
}

\begin{abstract}
We develop an intertemporal asset pricing model where cash-flow news, discount-rate news, and their second moments are priced by the market. This model generalizes the market-return decomposition framework, showing that intertemporal considerations imply a decomposition of squared market returns (coskewness risk). Our model accounts for $68 \%$ of the return variation across portfolios sorted by size, book-to-market ratio, momentum, investment, and profitability for a modern U.S. sample period. Further, our findings highlight the importance of covariation risk, that is, the risk of simultaneous unfavorable shocks to cash flows and discount rates, in understanding equity risk premia.
\end{abstract}

\section{Introduction}

Understanding risk factors that explain variation in the cross section of expected stock returns is a fundamental issue in the asset pricing literature. One stream of research examines the determinants of expected stock returns within an intertemporal portfolio-selection framework (Campbell (1993), Bansal and Yaron (2004), Campbell and Vuolteenaho (2004), Bansal, Kiku, Shaliastovich, and Yaron (2014), and Campbell, Giglio, Polk, and Turley (2018)). ${ }^{1}$ Assuming

*Kalev, p.kalev@latrobe.edu.au, La Trobe University Business School; Saxena (corresponding author), k.saxena@unsw.edu.au, University of New South Wales Business School; and Zolotoy, 1.zolotoy@unimelb.edu.au, Melbourne Business School, University of Melbourne. We thank Henk Berkman, Tony Berrada, Graham Bornholt, John Campbell, Jennifer Conrad (the editor), Thomas Cosimano, Robert Dittmar (the referee), Jack Favilukis, Stefano Giglio, Bruce Grundy, Ron Masulis, Pavel Savor, Tom Smith, Erik Theissen, Alireza Tourani-Rad, Terry Walter, Xiaolu Wang, and seminar participants at the University of Auckland, the University of British Columbia, the University of Geneva, École Supérieure des Sciences Économiques et Commerciales (ESSEC) Business School, Auckland University of Technology, Griffith University, Royal Melbourne Institute of Technology (RMIT) University, the University of Melbourne, the University of New South Wales, the University of Queensland, the 2015 Centre for Applied Financial Studies Annual Finance Research Colloquium, the Auckland Finance Meeting, the Bachelier Finance Society World Congress in Brussels, and the China International Conference in Finance in Shenzhen for their helpful comments. We are grateful to Kenneth French for making his Web site data available for use in this study. The usual caveats apply.

${ }^{1}$ Merton's (1973) work is the seminal reference for an intertemporal capital asset pricing model (ICAPM) with stochastic investment opportunities. 
conditional log-normality and using linear approximations of the Epstein-Zin (1991) pricing kernel, these studies show that long-term investors care about not only a stock's covariance with the market portfolio (as in Sharpe (1964) and Lintner (1965)) but also the stock's covariance with fluctuations in the expected returns and variances of their investments. Another important strand of the asset pricing literature emphasizes the role of the nonlinearity of the pricing kernel while typically ignoring intertemporal hedging considerations (Kraus and Litzenberger (1976), Lim (1989), Harvey and Siddique (2000), and Barone-Adesi, Gagliardini, and Urga (2004)). These studies model a pricing kernel in which both the covariance and the coskewness of a risky asset (i.e., the covariance of asset returns with the square of market returns) are priced.

Our study is positioned at the intersection of these two strands of literature. Recognizing the importance of accounting for both intertemporal investor considerations and the nonlinearity of the pricing kernel, we develop a nonlinear intertemporal asset pricing model (nonlinear ICAPM). We show that intertemporal investor considerations coupled with the nonlinearity of the pricing kernel give rise to an asset pricing model in which cash-flow news, discount-rate news, and their second moments are priced.

The intuition underlying our model builds on insights from the intertemporal asset pricing research (e.g., Campbell (1993), Campbell and Vuolteenaho (2004)). Consistent with the value of an asset being the discounted stream of projected cash flows and using the assumption of log-normally distributed returns, these studies show that long-term investors are concerned about two types of risk: i) the risk of receiving bad news about future cash flows and ii) the risk of an increase in the discount rate. In the first case, wealth decreases and investment opportunities are unchanged, whereas in the second case, wealth decreases but future investment opportunities are expected to improve, thereby partially compensating investors for the current decline in their wealth (Campbell and Vuolteenaho (2004)).

Our model shows that when the assumption of log-normally distributed returns is relaxed, long-term investors are also concerned about the risks from the second-order moments of cash-flow and discount-rate news. ${ }^{2}$ The importance of accounting for these risks arises from investor prudence, that is, the propensity to engage in precautionary savings in order to forearm oneself against future uncertainty (Kimball (1990), Harvey and Siddique (1999)). Specifically, our model suggests that investors will have higher marginal utility when they simultaneously receive bad news about future cash flows and expect higher macroeconomic uncertainty. In such times, higher discount rates will reflect higher levels of macroeconomic uncertainty (for a given set of investment opportunities) and thus increased probabilities of future declines in wealth and consumption, rather than better investment opportunities as in Campbell and Vuolteenaho (2004). Our model attributes a higher risk premium to stocks that underperform during periods of simultaneous unfavorable shocks to cash flows and discount rates.

${ }^{2}$ As Campbell ((2003), pp. 815-816) points out, the assumption of conditional log-normality, although expedient for theoretical asset pricing modeling, is unrealistic given the patterns in stock returns documented by prior research. In particular, prior studies document that stock returns standardized by the conditional mean and conditional standard deviation are significantly skewed and fat tailed (Harvey and Siddique (1999), Bali, Mo, and Tang (2008)). 
Consistent with the previous discussion, our model includes the following news terms: i) cash-flow news, ii) discount-rate news, iii) cash-flow-variation news (the shock to squared cash-flow news), iv) discount-rate-variation news (the shock to squared discount-rate news), and v) covariation news (the shock to the product of cash-flow news and discount-rate news). The first two news terms are the components of unexpected market returns derived by Campbell and Vuolteenaho (2004), based on a linear approximation of the Epstein-Zin (1991) pricing kernel. The remaining three second-order terms are the products of coskewness risk decomposition, which we derive from the second-order approximation of the pricing kernel. ${ }^{3}$ These second-order terms do not appear in Campbell and Vuolteenaho's (2004) model, which is derived under the assumption of conditional log-normality. When this assumption is relaxed, the nonlinearity of the Epstein-Zin (1991) pricing kernel implies that second-order components capture states in which pricing kernel realizations deviate substantially from their mean (Chen, Cosimano, and Himonas (2013)). ${ }^{4}$ Our model implies that investors are willing to pay a premium for assets that hedge an increase in the stand-alone variations of cash-flow news and discount-rate news. The covariation effect works in the opposite direction to the variation effect: Investors are willing to pay a premium to hedge the risk of being hurt simultaneously by unfavorable cash-flow news and unfavorable discount-rate news.

We evaluate the performance of our model using the cross section of portfolio returns sorted by size, book-to-market ratio, past stock performance (momentum), investments, and profitability. ${ }^{5}$ We find that small-cap stocks have greater exposure to covariation risk compared with large-cap stocks. Further, we find that stocks with good past performance (past winners) have greater exposure to covariation risk compared with stocks with poor past performance (past losers). The model explains $68 \%$ of the return variation across our test portfolios and is not rejected at conventional significance levels. Furthermore, we find that the explanatory power of coskewness decomposition is predominantly attributed to covariation risk, which carries a positive and statistically significant risk premium. To gauge the robustness of our findings, we estimate our model using

${ }^{3}$ To illustrate the baseline intuition behind our coskewness risk decomposition, consider the decomposition of market returns $\left(r_{t}\right)$ by Campbell and Vuolteenaho (2004): $r_{t}=N_{c, t}-N_{d, t}$, where $N_{c, t}$ denotes news to cash flows, and $N_{d, t}$ denotes news to discount rates. This implies that the square of the unexpected market return can be decomposed into cash-flow variation, discount-rate variation, and covariation terms: $r_{t}^{2}=N_{c, t}^{2}+N_{d, t}^{2}-2 N_{c, t} N_{d, t}$. Consequently, the coskewness risk (i.e., the covariance of asset returns with the square of market returns) decomposes into three components associated with these terms. Our model suggests that long-term investors with Epstein-Zin (1991) preferences assign different prices of risk to these three components of coskewness risk.

${ }^{4}$ Dittmar (2002) finds that nonlinear pricing kernels (restricted by preferences) are able to significantly improve upon linear pricing kernels in explaining the cross section of returns. Consistent with this view, we find that the second-order approximation of the Epstein-Zin (1991) pricing kernel performs well, whereas its linear approximation induces significant approximation errors, especially in bad states.

${ }^{5}$ Asset pricing models are often evaluated based on their ability to explain the size and value effects (e.g., Hodrick and Zhang (2001), Campbell and Vuolteenaho (2004), and Hahn and Lee (2006)). Jegadeesh and Titman (1993) is the seminal reference for the momentum effect. Novy-Marx (2013) and Fama and French (2015) examine the performance of asset pricing models using profitability- and investment-sorted portfolios. 
the approach of implied cost of equity for a panel of individual stocks (Lee, $\mathrm{Ng}$, and Swaminathan (2009), Chen, Chen, and Wei (2011)) and obtain qualitatively similar results.

Collectively, our results suggest that investors demand a higher risk premium for holding stocks with greater exposure to covariation risk, that is, stocks that have low returns when investors simultaneously receive bad news about both future cash flows and future discount rates. An intuitive way to summarize the mechanism that gives rise to the covariation risk premium is to say that covariation risk reflects the risk of bad news about cash flows to be accompanied by bad news about the discount rate. After such a "double-whammy" shock to cash flows and discount rates, covariance between the future-cash-flow and discountrate news also decreases. In such times, unfavorable news about decreasing future cash flows is less likely to be offset by favorable news about future investment opportunities and vice versa. Instead, investors are likely to apply higher discount rates to future cash flows due to an increase in macroeconomic uncertainty and an associated higher precautionary savings motive against future declines in wealth. Consequently, stocks with greater exposure to such double-whammy events will have higher expected returns to compensate for such risk.

We contribute to the asset pricing literature by developing an asset pricing model that incorporates both intertemporal investor considerations and the nonlinearity of the pricing kernel. Our model generalizes the market return decomposition framework of Campbell and Vuolteenaho (2004), showing that intertemporal considerations imply the decomposition of squared market returns (coskewness risk) into its cash-flow variation, discount-rate variation, and covariation risk components. We also contribute to the stream of research examining the role of coskewness risk in shaping the expected return-risk relation (Harvey and Siddique (2000), Dittmar (2002), and Barone-Adesi et al. (2004)). We demonstrate, both theoretically and empirically, that coskewness risk decomposition is important in understanding asset pricing when the assumption of conditional lognormality is violated. Our model suggests that not only the magnitude of exposure to coskewness risk but also the source of coskewness risk should be considered. Specifically, our findings show that the contribution of coskewness risk to explaining cross-sectional variation in expected stock returns is predominantly driven by the covariation risk component, in that stocks with greater exposure to covariation risk have higher expected returns.

The remainder of the article is organized as follows: Sections II and III present our analytical framework. Section IV describes the estimation of news components implied by our model. Empirical results are presented and discussed in Section V. Section VI concludes.

\section{Theoretical Framework}

We begin by outlining several results from prior research that are helpful for the derivation of our model. Our starting point is a no-arbitrage condition that implies the standard Euler equation:

$$
\mathrm{E}_{t}\left[M_{t+1} R_{i, t+1}\right]=1,
$$


where $M_{t+1}$ denotes the stochastic discount factor (SDF), and $R_{i, t+1}$ denotes the return on any traded asset in the economy (Harrison and Kreps (1979)). The expression for the SDF depends on the preferences of the representative agent and the intertemporal budget constraint. Following prior research (Campbell and Vuolteenaho (2004), Bansal et al. (2014), and Campbell et al. (2018)), we consider a representative agent with the Epstein-Zin (1989) recursive preferences. This assumption has the desirable property that the notion of risk aversion is separated from that of the intertemporal elasticity of substitution (IES) (Campbell (2003)). Epstein and Zin (1991) show that these preferences coupled with the intertemporal budget constraint imply the following $\operatorname{SDF}\left(M_{t+1}\right)$ for a representative agent:

$$
M_{t+1}=\left\{\delta\left(\frac{C_{t+1}}{C_{t}}\right)^{-1 / \psi}\right\}^{\theta} R_{t+1}^{-(1-\theta)}
$$

where $R_{t+1}$ is the return on the aggregate wealth $W_{t}$, with $W_{t}$ defined as the market value of the consumption stream $\left\{C_{t}\right\}$ (including current consumption) owned by the representative agent. In equation (2), $\theta$ equals $(1-\gamma) /(1-1 / \psi)$, where $\gamma$ is the risk aversion coefficient, $\psi$ is the IES, and $\delta$ is the discount factor.

\section{A. An SDF with Second-Order Shocks}

Our approach is to derive an expression for the SDF in terms of the two news components of the unexpected market returns, that is, cash-flow news $\left(N_{c, t+1}\right)$ and discount-rate news $\left(N_{d, t+1}\right)$. To do so, we first derive an approximation for the pricing kernel outlined in equation (2) using a second-order Taylor expansion. For analytical tractability, we first express the right-hand side of equation (2) in terms of natural logs and then approximate the equation using a second-order Taylor expansion around the conditional expectations of $r_{t+1}$ and $\Delta c_{t+1}$, where lowercase letters denote natural logs. This approach yields an approximation of the $\mathrm{SDF}$ around $\rho=\exp \left(\mathrm{E}\left[m_{t+1}\right]\right)$. For notational convenience, we define unexpected market return as $\omega_{r, t+1}=r_{t+1}-E_{t} r_{t+1}$. Similarly, we define unexpected consumption growth as $\omega_{c, t+1}=\Delta c_{t+1}-E_{t} \Delta c_{t+1}$. The second-order Taylor expansion of equation (2) produces equation (3a). For convenience, we rearrange the expression in equation (3a) to obtain equation ( $3 b)$ :

$$
\begin{aligned}
M_{t+1}-E_{t} M_{t+1} \cong & E_{t} M_{t+1}\left\{-\frac{\theta}{\psi} \omega_{c, t+1}-(1-\theta) \omega_{r, t+1}\right. \\
& \left.+\frac{1}{2}\left[\left(\frac{\theta}{\psi} \omega_{c, t+1}+(1-\theta) \omega_{r, t+1}\right)^{2}-h_{m, t}\right]\right\}, \\
\omega_{m, t+1}= & \frac{1}{E_{t} M_{t+1}}\left(M_{t+1}-E_{t} M_{t+1}\right) \\
= & R_{f, t}\left(M_{t+1}-E_{t} M_{t+1}\right) \\
= & -\frac{\theta}{\psi} \omega_{c, t+1}-(1-\theta) \omega_{r, t+1}+\frac{1}{2} \omega_{v, t+1},
\end{aligned}
$$


where

$$
\begin{aligned}
\omega_{v, t+1} & =\left[\left\{\frac{\theta}{\psi} \omega_{c, t+1}+(1-\theta) \omega_{r, t+1}\right\}^{2}-h_{m, t}\right], \\
h_{m, t} & =\mathrm{E}_{t}\left[\left\{\frac{\theta}{\psi} \omega_{c, t+1}+(1-\theta) \omega_{r, t+1}\right\}^{2}\right] \\
& =\operatorname{var}_{t}\left[\frac{\theta}{\psi} \omega_{c, t+1}+(1-\theta) \omega_{r, t+1}\right] .
\end{aligned}
$$

Equation (3b) shows that the percentage deviation in the SDF from its expected value depends on the following items: i) shocks to log consumption growth $\left(\omega_{c, t+1}\right)$, ii) shocks to log market return $\left(\omega_{r, t+1}\right)$, and iii) a second-order approximation of shocks to the square of $\log \operatorname{SDF}\left(\omega_{v, t+1}\right) .^{6}$

\section{B. News Components of the Pricing Kernel}

Our next step is to express shocks to the pricing kernel $\omega_{m, t+1}$ in equation (3b) without direct reference to consumption (Campbell (1993)). To do so, we first obtain approximate expressions for the expected log consumption growth $\mathrm{E}_{t} \Delta c_{t+1}$ by imposing the restriction that equation (1) holds for any asset $i$, including the market portfolio (aggregate wealth portfolio). That is, in equation (1), we substitute $R_{i, t+1}$ with the market portfolio return and $M_{t+1}$ with the SDF given in equation (2). This provides a Euler equation expressed in terms of aggregate consumption growth and market returns. Next, we derive a second-order Taylor expansion to this Euler equation around the conditional means of $r_{t+1}$ and $\Delta c_{t+1}$ to obtain an expression for expected consumption growth (Campbell, Chan, and Viceira (2003)):

$$
\mathrm{E}_{t} \Delta c_{t+1}=\psi \log \delta+\psi \mathrm{E}_{t} r_{t+1}+\frac{1}{2} \frac{\theta}{\psi} \operatorname{var}_{t}\left[\Delta c_{t+1}-\psi r_{t+1}\right]
$$

Equation (4) relates expected consumption growth to expected returns on wealth and a precautionary savings term (the variance of future consumption growth relative to portfolio returns, $\left.h_{p, t}=\operatorname{var}_{t}\left[\Delta c_{t+1}-\psi r_{t+1}\right]\right)$. The sensitivity of expected consumption growth to changes in expected returns is measured by the IES coefficient $(\psi)$. The precautionary savings term $h_{p, t}$ measures the influence of economic uncertainty on the expected consumption growth. Equation (4) shows that when $\theta<0(\theta>0)$, an increase in $h_{p, t}$ decreases (increases) expected consumption growth. Applying equation (4) to a log-linearization of the intertemporal budget constraint yields the following expression for unexpected log consumption

\footnotetext{
${ }^{6}$ As discussed previously, in developing our model we rely on a second-order Taylor expansion of a pricing kernel. This approach could raise questions regarding i) the accuracy of such an approximation and ii) the incremental value of such an approximation compared with the standard log-linear approximation approach used in prior studies. To examine these two issues, we conduct a small-scale test in which we examine the approximation errors implied by the second-order expansion of a pricing kernel versus those implied by the first-order expansion. The results (discussed in Appendix A) suggest that second-order expansion provides a reasonably accurate approximation of a pricing kernel. The results also suggest that second-order expansion provides a significant improvement in terms of the magnitude of approximation errors compared with the first-order expansion.
} 
growth in terms of the news components:

$$
\begin{aligned}
\omega_{c, t+1} & =\Delta c_{t+1}-\mathrm{E}_{t} \Delta\left[c_{t+1}\right] \\
& =\left(\mathrm{E}_{t+1}-\mathrm{E}_{t}\right) \sum_{j=0}^{\infty} \rho^{j} r_{t+1+j}-\left(\mathrm{E}_{t+1}-\mathrm{E}_{t}\right) \sum_{j=1}^{\infty} \rho^{j} \Delta c_{t+1+j} \\
& =N_{c, t+1}-\psi N_{d, t+1}+\frac{1}{2} \frac{\psi}{\theta} N_{p, t+1},
\end{aligned}
$$

where

$$
\begin{aligned}
& N_{c, t+1}=\left(\mathrm{E}_{t+1}-\mathrm{E}_{t}\right) \sum_{s=0}^{\infty} \rho^{s} \Delta c_{j, t+1+s}, \\
& N_{d, t+1}=\left(\mathrm{E}_{t+1}-\mathrm{E}_{t}\right) \sum_{s=1}^{\infty} \rho^{s} r_{j, t+1+s}, \\
& N_{p, t+1}=\left(\mathrm{E}_{t+1}-\mathrm{E}_{t}\right) \sum_{j=1}^{\infty} \rho^{j} \operatorname{var}_{t}\left[\frac{\theta}{\psi} \Delta c_{t+1}-\theta r_{t+1}\right] .
\end{aligned}
$$

In equation (5), $N_{c, t+1}$ denotes cash-flow news, and $N_{d, t+1}$ denotes discountrate news (Campbell and Vuolteenaho (2004)). The last term, $N_{p, t+1}$, denotes precautionary-savings news, which captures revisions in expectations of long-run economic uncertainty that will influence the level of long-term investors' precautionary savings.

To obtain an analytically tractable expression for precautionary savings news, we solve for the precautionary-savings term $h_{p, t}$ as a function of the cash-flow and discount-rate news components. Using equation (4) and the return decomposition relation $\left(\omega_{r, t+1}=N_{c, t+1}-N_{d, t+1}\right)$, we obtain $h_{p, t}=$ $\operatorname{var}_{t}\left[(1-\gamma) N_{c, t+1}+1 / 2 N_{p, t+1}\right]$. Substituting this expression in the definition for precautionary-savings news, we obtain

$$
N_{p, t+1}=\left(\mathrm{E}_{t+1}-\mathrm{E}_{t}\right) \sum_{j=1}^{\infty} \rho^{j}\left[\left((1-\gamma) N_{c, t+1+j}+\frac{1}{2} N_{p, t+1+j}\right)^{2}\right] .
$$

Equation (6) suggests that precautionary savings news depends on the following three items: i) news about the long-run variance of cash-flow news, ii) news about the long-run variance of precautionary-savings news, and iii) news about the longrun covariance between the two. Intuitively, economic uncertainty (volatility) influences not only precautionary savings but also the uncertainty of how uncertain the future is going to be (i.e., the volatility of volatility). To simplify the expression for precautionary-savings news, we specify a volatility process for cash-flow news and discount-rate news in the next section.

Next, we express innovations to our pricing kernel by plugging the expression for $\omega_{c, t+1}$ from equation (5) into equation (3b), which leads to the following equation:

$$
\omega_{m, t+1}=-\gamma N_{c, t+1}+N_{d, t+1}+\frac{1}{2} N_{p, t+1}+\frac{1}{2} \omega_{v, t+1} .
$$


The pricing kernel in equation (7) generalizes the pricing kernels derived by Bansal et al. (2014) and Campbell et al. (2018), in that the shocks to the squared $\log \operatorname{SDF}\left(\omega_{v, t+1}\right)$ are also priced in our framework. The difference arises because these studies assume conditional log-normality and therefore ignore second-order SDF shocks, which are potentially important in the data. For example, Harvey and Siddique (2000) show that differences in the covariance with the square of the market returns help explain cross-sectional variation in risk premia. Equation (7) allows for these second-order effects in the ICAPM return decomposition framework.

\section{Nonlinear ICAPM with Coskewness Risk Decomposition}

Recall that our modeling approach is to derive an expression for the pricing kernel in terms of the two components of the unexpected market return: cash-flow news and discount-rate news. However, the pricing kernel in equation (7) depends not only on these two components but also on the precautionary-savings news $\left(N_{p, t+1}\right)$ and shocks to the square of $\log \operatorname{SDF}\left(\omega_{v, t+1}\right)$. In this section, we derive expressions for $N_{p, t+1}$ and $\omega_{v, t+1}$ in terms of $N_{c, t+1}$ and $N_{d, t+1}$.

Equations (3) and (6) show that both $\omega_{v, t+1}$ and $N_{p, t+1}$ are functions of the IES. In what follows, we derive expressions for these two terms in terms of $N_{c, t+1}$ and $N_{d, t+1}$ under two separate scenarios. In the first scenario, we assume the IES to be close to 1, as in Campbell and Vuolteenaho (2004). In the second scenario, we consider a more general model where we allow IES to be significantly greater than 1. The distinction between these two scenarios helps us examine the role of coskewness risk decomposition in the two asset pricing environments. When the IES is close to 1, volatility risk has no substantial effect on investor marginal utility and hedging demands (Campbell and Vuolteenaho (2004)). In contrast, when risk aversion and the IES are not equal and are both greater than 1, agents have a stronger precautionary savings motive. That is, long-term investors demand larger risk premia for holding assets exposed to the risk of a long-run rise in economic uncertainty (volatility risk). Accordingly, our first scenario focuses on modeling the effect of coskewness risk decomposition, absent any effect of second-moment news on future volatility. The second scenario extends our model to incorporate volatility risk and its effect on the precautionary-savings motive.

\section{A. Nonlinear ICAPM with Coskewness Risk Decomposition: IES Close to 1}

\section{Pricing Kernel}

In this section, we consider the scenario when the IES of a representative investor is close to 1, as in Campbell and Vuolteenaho (2004). As noted earlier, under this assumption, the precautionary savings term $N_{p, t+1}$ becomes negligible. Hence, the remaining task is to derive an expression for $\omega_{v, t+1}$ in terms of $N_{c, t+1}$ and $N_{d, t+1}$.

To derive an expression for $\omega_{v, t+1}$ in terms of $N_{c, t+1}$ and $N_{d, t+1}$, we eliminate the third- and higher-order terms of $N_{c, t+1}$ and $N_{d, t+1}$ from the expression of the SDF. Note that the third- and higher-order terms of $N_{p, t+1}$ do not contribute to the second-order approximation of $\omega_{v, t+1}=\left[\left\{(\theta / \psi) \omega_{c, t+1}+(1-\theta) \omega_{r, t+1}\right\}^{2}-h_{m, t}\right]$. 
This result further implies that the expression for $\omega_{v, t+1}$ in terms of first- and second-order terms of $N_{c, t+1}$ and $N_{d, t+1}$, after eliminating higher-order terms, is given by

$$
\begin{aligned}
\omega_{v, t+1} \approx\left(\mathrm{E}_{t+1}-\mathrm{E}_{t}\right)\left(-\gamma N_{c, t+1}+N_{d, t+1}\right)^{2} \\
=\gamma^{2} N_{c c, t+1}+N_{d d, t+1}-2 \gamma N_{c d, t+1},
\end{aligned}
$$

where $N_{c c, t+1}, N_{d d, t+1}$, and $N_{c d, t+1}$ are news about the second-order terms of $N_{c, t+1}$ and $N_{d, t+1}$, given by $N_{c, t+1}^{2}-h_{c c, t}, N_{d, t+1}^{2}-h_{d d, t}$, and $N_{c, t+1} N_{d, t+1}-h_{c d, t}$, respectively, where $h$ denotes the conditional variance or covariance of the corresponding news terms.

We plug this expression into equation (7) to obtain the following expression for our SDF:

$$
\omega_{m, t+1}=-\gamma N_{c, t+1}+N_{d, t+1}+\frac{\gamma^{2}}{2} N_{c c, t+1}+\frac{1}{2} N_{d d, t+1}-\gamma N_{c d, t+1} .
$$

Substituting equation (9) into equation (1) yields an approximate pricing expression for the expected excess return on any traded asset:

$$
\begin{aligned}
E_{t} R_{i, t+1}-R_{f, t}= & -R_{f, t} \operatorname{cov}_{t}\left[M_{t+1}, R_{i, t+1}\right] \\
\approx & \gamma \operatorname{cov}_{t}\left[r_{i, t+1}, N_{c, t+1}\right]+\operatorname{cov}_{t}\left[r_{i, t+1},-N_{d, t+1}\right] \\
& +\lambda_{c c} \operatorname{cov}_{t}\left[r_{i, t+1}, N_{c c, t+1}\right]+\lambda_{d d} \operatorname{cov}_{t}\left[r_{i, t+1}, N_{d d, t+1}\right] \\
& +\lambda_{c d} \operatorname{cov}_{t}\left[r_{i, t+1}, N_{c d, t+1}\right],
\end{aligned}
$$

where $\lambda_{c c}=-\gamma^{2} / 2, \lambda_{d d}=-1 / 2$, and $\lambda_{c d}=\gamma$. Equation (10) suggests that investors will pay a premium to hold assets that positively covary with cash-flow-variation shocks $\left(N_{c c, t+1}\right)$ and discount-rate-variation shocks $\left(N_{d d, t+1}\right)$ but will demand a premium to hold assets that positively covary with double-whammy shocks $\left(N_{c d, t+1}\right)$. In what follows, we refer to this model as the coskewness risk decomposition ICAPM (ICAPM-CRD).

\section{Relation to Other Asset Pricing Models}

Among other asset pricing models, this model is most closely related to the capital asset pricing model (CAPM) with the coskewness of Kraus and Litzenberger (1976) and its conditional version developed by Harvey and Siddique (2000). In these models, the coskewness of a risky asset (i.e., the covariance of asset returns with the square of market returns) is priced, and the expected return on a risky asset is negatively related with the covariance of an asset return with the square of market return. Harvey and Siddique (2000) note that such a pricing kernel can be derived in an infinite-horizon economy with logarithmic investor preferences.

The key difference between our model with coskewness risk decomposition (ICAPM-CRD) and that of Kraus and Litzenberger (1976) and Harvey and Siddique (2000) is that we consider a long-term investor with Epstein-Zin (1989) preferences, which nest logarithmic preferences as a special case. Therefore, our model can be viewed as a generalization of the models of Kraus and Litzenberger (1976) and Harvey and Siddique (2000). In the special case, when $\gamma=1$, our 
conditional pricing kernel is expressed only in terms of the unexpected market portfolio's returns $\left[\omega_{m, t+1}=-\omega_{r, t+1}+0.5\left[\omega_{r, t+1}^{2}-\mathrm{E}_{t} \omega_{r, t+1}^{2}\right]\right]$ and is thus analogous to a conditional version of the pricing kernel of Harvey and Siddique (2000).

\section{B. Nonlinear ICAPM with Coskewness Risk Decomposition: IES Greater than 1}

\section{Pricing Kernel}

In this section, we consider the scenario where the IES is substantially greater than 1 . In this case, the precautionary savings term and thus volatility risk influence our pricing kernel. The dynamics of this precautionary savings term, in turn, depend on the dynamics of the conditional covariance matrix of $N_{c, t+1}$ and $N_{d, t+1}$. We assume that their conditional covariance matrix, $\mathbf{H}_{t}$, follows a multivariate generalized autoregressive conditional heteroscedasticity (MGARCH) process. In Appendix B, we show that these assumptions allow us to express our pricing kernel as follows:

$$
\omega_{m, t+1}=-\gamma N_{c, t+1}+N_{d, t+1}-\lambda_{c c} N_{c c, t+1}-\lambda_{d d} N_{d d, t+1}-\lambda_{c d} N_{c d, t+1} .
$$

The expressions for $\lambda_{c c}, \lambda_{d d}$, and $\lambda_{c d}$ are, respectively, as follows:

$$
\begin{aligned}
& \lambda_{c c}=-\frac{\gamma^{2}+(\gamma-1)^{2} \chi a_{c c}^{2}}{2}, \\
& \lambda_{d d}=-\frac{1+(\gamma-1)^{2} \chi a_{d c}^{2}}{2}, \\
& \lambda_{c d}=\gamma-(\gamma-1)^{2} \chi a_{d c} a_{c c},
\end{aligned}
$$

where $a_{x y}$ denotes an element of $\mathbf{A}$, the autoregressive conditional heteroscedasticity $(\mathrm{ARCH})$ persistence matrix defined in equation (B-1); and $\chi$ is a scale parameter that captures the link between news about long-run aggregate volatility and the variance of the next period's cash-flow news $\left(h_{c c, t+1}\right)$.

From the expressions in equations (12a) and (12b), we note that $\lambda_{c c}, \lambda_{d d}<0$. In addition, equation (12c) implies that $\lambda_{c d}>0$ when $a_{d c} a_{c c}<0$ or $\gamma>(\gamma-1)^{2} \chi a_{d c} a_{c c}$. The condition $a_{d c} a_{c c}<0$ implies that a double-whammy shock increases future cash-flow volatility $\left(N_{c, t} N_{d, t}<0 \Rightarrow \uparrow h_{c c, t+1}\right)$. Consistent with our conjecture of a positive covariation risk premium $\left(\lambda_{c d}>0\right)$, we find that $a_{d c} a_{c c}<0$ for our estimated MGARCH parameters (discussed in further detail in Section IV). Substituting equation (11) into equation (1) yields an approximate pricing expression for the expected excess return on any traded asset similar to equation (10), but with different risk premia coefficients. We label this model ICAPM-CRD-MGARCH.

\section{Relation to Other Asset Pricing Models}

Our second model (ICAPM-CRD-MGARCH) generalizes the first one (ICAPM-CRD) to allow for volatility risks. The volatility-news mechanism amplifies the magnitude of the risk-premium parameters for the same second-order shocks because investors are averse to increases in long-term volatility. In the special case of constant volatility, when the ARCH parameters are 0 , we obtain the model described in the previous section. 
Our second model is also related to Bansal and Yaron (2004), Bansal et al. (2014), and Campbell et al. (2018), who model the implications of volatility news within the ICAPM framework. A fundamental difference between these models and our model is that in our model, shocks to the second-order terms of cash-flow and discount-rate news are also priced. This difference arises for two reasons: First, the aforementioned studies assume conditional log-normality and therefore suppress shocks to the square of the SDF. Second, these studies do not decompose volatility risk into its variation and covariation components. Our model allows for variation in market returns to be driven by three distinct sources: variations in cash-flow news and discount-rate news and the covariation between the two.

\section{Estimation of the News Components}

\section{A. Estimation of Cash-Flow News and Discount-Rate News}

We estimate cash-flow news and discount-rate news following Campbell and Vuolteenaho (2004). Specifically, we assume that the dynamics of the relevant state variables are captured by a first-order vector autoregression (VAR) process:

$$
\mathbf{x}_{t+1}=\overline{\mathbf{x}}+\boldsymbol{\Gamma}\left(\mathbf{x}_{t}-\overline{\mathbf{x}}\right)+\mathbf{u}_{t+1},
$$

where $\mathbf{x}_{t}$ is an $n \times 1$ vector of state variables with the log market excess returns as the first element, $\overline{\mathbf{x}}$ is an $n \times 1$ vector of constants, $\Gamma$ is an $n \times n$ matrix of VAR coefficients, and $\mathbf{u}_{t+1}$ is an $n \times 1$ vector of shocks to the state variables with conditional mean 0 . The cash-flow news $\left(N_{c, t+1}\right)$ and discount-rate news $\left(N_{d, t+1}\right)$ components of the unexpected market return are expressed as $N_{d, t+1}=\mathbf{e}_{1}^{\prime} \lambda \mathbf{u}_{t+1}$ and $N_{c, t+1}=\left(\mathbf{e}_{1}^{\prime}+\mathbf{e}_{1}^{\prime} \lambda\right) \mathbf{u}_{t+1}$, where the matrix $\lambda=\rho \boldsymbol{\Gamma}(\mathbf{I}-\rho \boldsymbol{\Gamma})^{-1}$ maps instantaneous state-variable shocks to the news components of unexpected excess returns, and $\mathbf{e}_{1}$ is a vector with 1 as the first element and 0 s as the remaining elements. ${ }^{7}$

Following Campbell and Vuolteenaho (2004), we estimate equation (13) using a $4 \times 1$ vector of state variables that has the excess market return as the first element and three other variables that help to predict excess market returns: the term spread, the small value spread, and the natural log of the cyclically adjusted price-earnings ratio (see Campbell and Vuolteenaho (2004) for details). Following Campbell and Vuolteenaho (2004), we set the discount coefficient $\rho$ equal to 0.95 in annual terms.

The coefficients of the VAR and the summary statistics for the cash-flow news and discount-rate news for our sample period are reported in Panels A and B of Table 1, respectively. The mean of $N_{c}$ is $-0.06 \%$, and the mean of $N_{d}$ is $-0.05 \%$. The standard deviation of the cash-flow news is $2.32 \%$, much smaller than the standard deviation of the discount-rate news of $4.36 \%$, consistent with the results of Campbell and Vuolteenaho (2004).

\footnotetext{
${ }^{7}$ Engle and Kroner (1995) note that such a system can be consistently estimated without imposing the GARCH error structure (which we assume for our ICAPM-CRD-MGARCH model) because the error term vector $\mathbf{u}_{t+1}$ is uncorrelated with $\mathbf{x}_{t}$. Although more efficient estimates can be obtained by accounting for the error structure in the first-stage vector autoregression (VAR), we prefer a parsimonious estimation so that the incremental effects of the second-order terms in comparison to existing models can be understood.
} 
TABLE 1

Descriptive Statistics of Market Returns, Cash-Flow News, and Discount-Rate News

Panel A of Table 1 shows the ordinary least squares (OLS) parameter estimates for a first-order vector autoregression (VAR) model including a constant, the log excess market return ( $\left.r_{\mathrm{MKT}}^{e}\right)$, the term yield spread (TY), the price-to-earnings ratio (PE), and the small-stock value spread (VS). Each set of four rows corresponds to a different dependent variable. The first four columns report the coefficients of the four explanatory variables, and the remaining columns show $R^{2}$ and $F$-statistics. Following Campbell and Vuolteenaho (2004), we set the discount coefficient $\rho$ equal to 0.95 in annual terms and estimate the parameters of the VAR system using the sample period from Jan. 1929 to Dec. 2010. In Panel B, we report selected descriptive statistics for unexpected market returns and the estimates of the cash-flow news and discountrate news for both the full sample period (i.e., Jan. 1929-Dec. 2010) and the modern sample period (i.e., July 1963Dec. 2010). The cash-flow news $\left(N_{c}\right)$ and discount-rate news $\left(-N_{d}\right)$ are estimated following Campbell and Vuolteenaho (2004). The conditional covariance matrix of the cash-flow news $\left(N_{c}\right)$ and discount-rate news $\left(N_{d}\right)$ is assumed to follow a multivariate generalized autoregressive conditional heteroscedasticity (MGARCH) process. The estimated coefficients of this process are presented in Panel $\mathrm{C}$. The monthly means and standard deviations are reported in percentage points. Panel $C$ reports the MGARCH parameters of the volatility process of $N_{c}$ and $N_{d}$ : The matrix A contains the autoregressive conditional heteroscedasticity (ARCH) coefficients, the matrix $\mathrm{G}$ contains the generalized autoregressive conditional heteroscedasticity (GARCH) coefficients, and the matrix $\mathrm{C}$ contains the intercept parameters. The first element represents the cash flows, and the second represents the discount rates.

Panel A. VAR Parameter Estimates (1929-2010)

\begin{tabular}{|c|c|c|c|c|c|c|}
\hline & $r_{\mathrm{MKT}, t-1}^{e}$ & $T Y_{t-1}$ & $\mathrm{PE}_{t-1}$ & $\mathrm{VS}_{t-1}$ & $R^{2}$ & $F$ \\
\hline$r_{\mathrm{MKT}}^{e}$ & 0.109 & 0.004 & -0.016 & -0.011 & 0.03 & 6.7 \\
\hline TY & -0.011 & 0.938 & -0.003 & 0.053 & 0.89 & $1.9 \mathrm{E}+03$ \\
\hline PE & 0.518 & 0.001 & 0.992 & -0.003 & 0.99 & $2.5 \mathrm{E}+04$ \\
\hline VS & -0.013 & -0.001 & -0.001 & 0.991 & 0.98 & $1.4 \mathrm{E}+04$ \\
\hline
\end{tabular}

Panel B. Summary Statistics

1929-2010

\begin{tabular}{|c|c|c|c|c|c|c|c|c|c|c|}
\hline & \multicolumn{5}{|c|}{$1929-2010$} & \multicolumn{5}{|c|}{2010} \\
\hline & Mean & Std. Dev. & $25 \%$ & Median & $75 \%$ & Mean & Std. Dev. & $25 \%$ & Median & $75 \%$ \\
\hline$N_{c}$ & 0.00 & 2.65 & -1.17 & 0.18 & 1.40 & -0.06 & 2.32 & -1.13 & 0.11 & 1.22 \\
\hline$N_{d}$ & 0.00 & 4.75 & -2.57 & 0.33 & 2.74 & 0.05 & 4.36 & -2.42 & 0.18 & 2.69 \\
\hline$N_{c}^{2} \times 10^{2}$ & 0.07 & 0.20 & 0.00 & 0.02 & 0.06 & 0.05 & 0.1 & 0.00 & 0.01 & 0.06 \\
\hline$N_{d}^{2} \times 10^{2}$ & 0.23 & 0.54 & 0.02 & 0.07 & 0.20 & 0.18 & 0.37 & 0.02 & 0.07 & 0.19 \\
\hline$N_{c} \times-N_{d} \times 10^{2}$ & 0.00 & 0.22 & -0.03 & 0.00 & 0.03 & -0.02 & 0.2 & -0.03 & -0.00 & 0.02 \\
\hline \multicolumn{11}{|c|}{ Panel C. Conditional Volatility Parameter Estimates } \\
\hline & \multicolumn{2}{|c|}{$\mathrm{C} \times 10^{4}$} & & \multicolumn{3}{|c|}{ A } & & \multicolumn{3}{|c|}{ G } \\
\hline$N_{c}$ & .00 & 3. & & -0.16 & & -0.64 & & -0.93 & & -0.03 \\
\hline$N_{d}$ & 3.46 & 13. & & 0.19 & & 0.17 & & 0.70 & & -0.37 \\
\hline
\end{tabular}

\section{B. Estimation of the Second-Moment News Terms}

The ICAPM-CRD makes no assumptions regarding the dynamics of the conditional expectations of $N_{c, t+1}^{2}, N_{d, t+1}^{2}$, and $N_{c, t+1} \times N_{d, t+1}$. Hence, to keep the estimation strategy parsimonious, for the ICAPM-CRD, we estimate news to the second-order terms by simply subtracting their unconditional mean. In contrast, for the ICAPM-CRD-MGARCH, we estimate news to these terms by subtracting their conditional means. For that purpose, we first fit the MGARCH model outlined in equation (B-1) to the time series of $N_{c, t+1}$ and $N_{d, t+1}$ and then use the estimates of the MGARCH model to calculate the conditional variances and covariance series of the cash-flow news and discount-rate news. Next, we estimate the shocks to the quadratics by subtracting the corresponding elements of the conditional covariance matrix predicted by the MGARCH model from the quadratics of the cash-flow news and discount-rate news.

In Panel C of Table 1, we report the estimated MGARCH coefficients. Recall that the sign of the covariation risk premium in the ICAPM-CRD-MGARCH is positive when $a_{d c} a_{c c}<0$. Consistent with our conjecture of a positive covariation risk premium, we estimate that $a_{d c} a_{c c}<0$. This reflects an investor's intertemporal 
preference for states when the discount-rate news has a high positive covariance with the cash-flow news so that shocks to cash flows and discount rates are likely to offset each other. Consistent with this notion, investors will require a higher risk premium for assets that yield low returns in states when the covariance between the cash-flow and discount-rate news is low, as reflected by $\lambda_{c d}>0$.

\section{Time Series of the News Components}

Figure 1 plots the time series of the cash-flow news and the discount-rate news. Figure 2 plots the conditional variances and covariance of the cash-flow news and discount-rate news obtained from a fitted MGARCH model and the shocks to the second-order terms of the cash-flow news and discount-rate news. Major shocks to the cash-flow news and discount-rate news generally seem to coincide with National Bureau of Economic Research (NBER) recessions. Further, the NBER recessions in our sample seem to coincide with increases in discount-rate variation. The cash-flow variation also increases during recessions, but the magnitude of the increase is lower compared with that of the discount-rate variation.

The conditional covariance between the cash-flow news and discount-rate news experiences a substantial decline in two of the recessions in our sample:

FIGURE 1

News Components of Market Returns

Figure 1 plots the time series of the cash-flow news (Graph A) and the negative of the discount-rate news (Graph B). The sample period is from July 1963 to Dec. 2010. The shaded areas represent National Bureau of Economic Research (NBER) recessions.

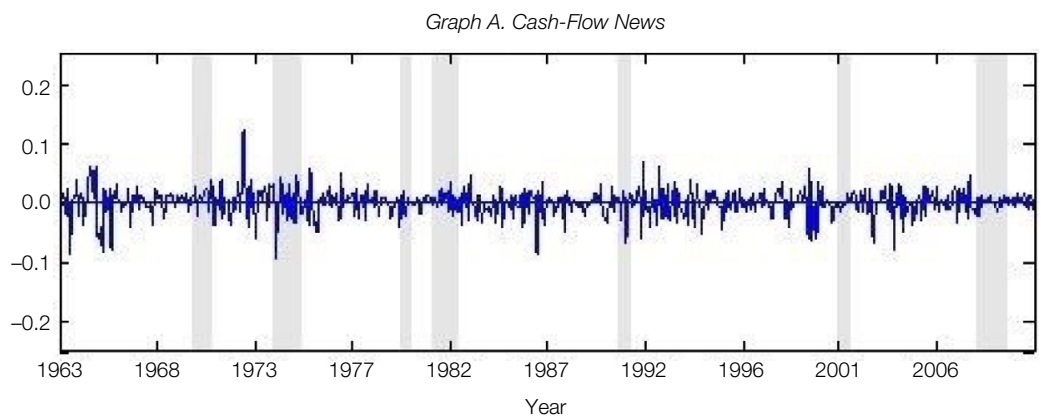

Graph B. Discount-Rate News

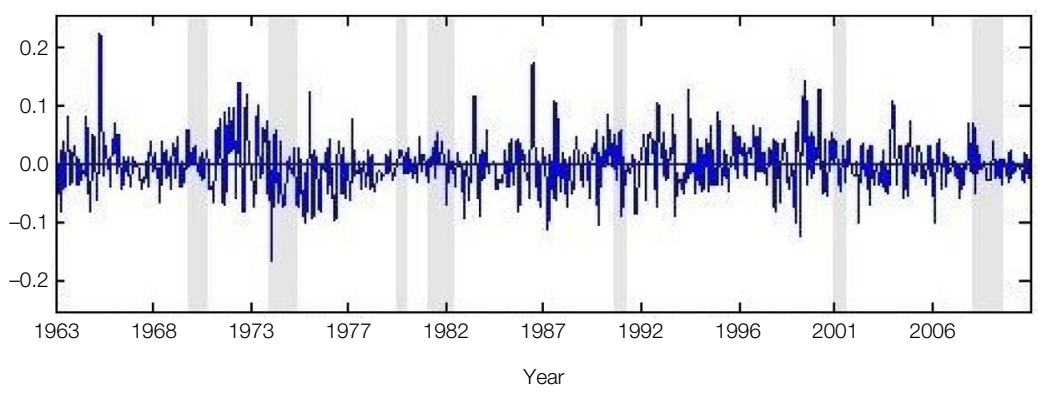




\section{FIGURE 2}

\section{Variances, Covariances, and Their News Components}

Graphs A and B of Figure 2 show the time series of the multivariate generalized autoregressive conditional heteroscedasticity (MGARCH) conditional variances and the covariance of cash-flow news and discount-rate news. Graphs $\mathrm{C}$ and $\mathrm{D}$ plot the shocks to these series. The sample period is from July 1963 to Dec. 2010. The shaded areas represent National Bureau of Economic Research (NBER) recessions.
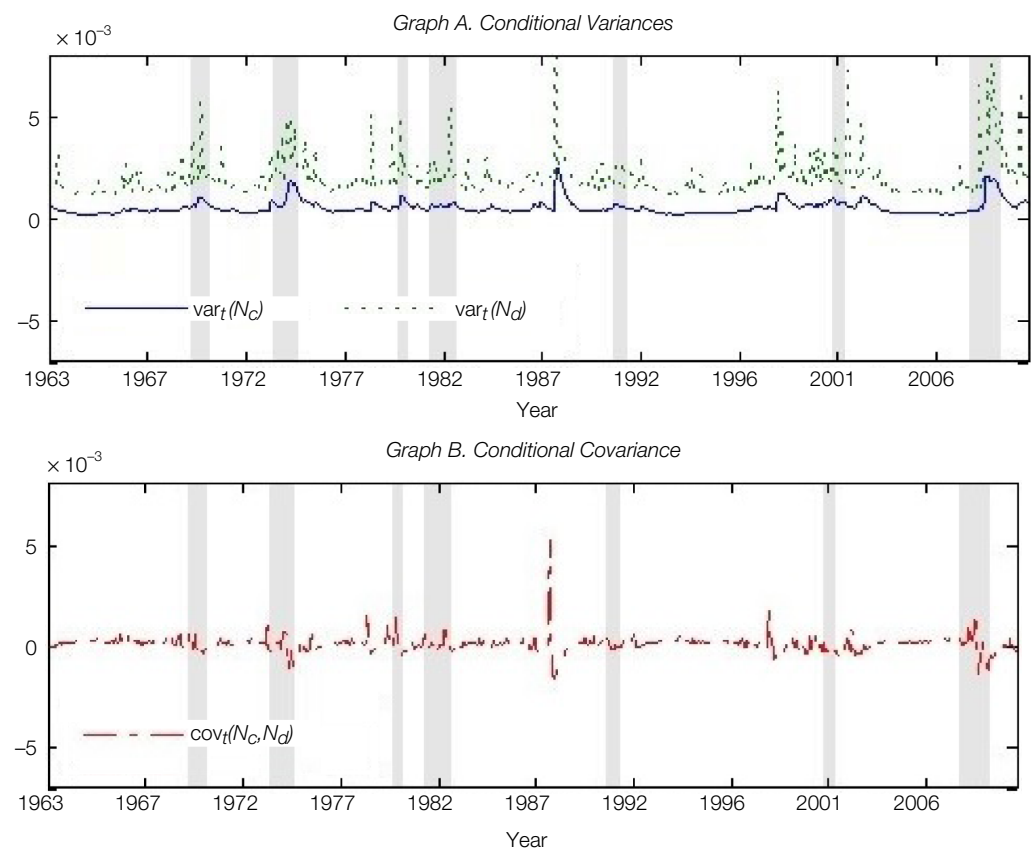

Graph C. Variation News

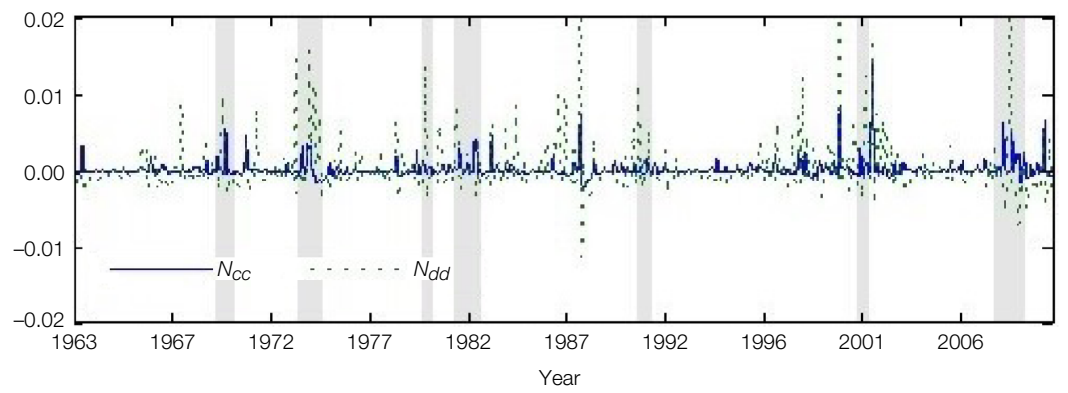

Graph D. Covariation News

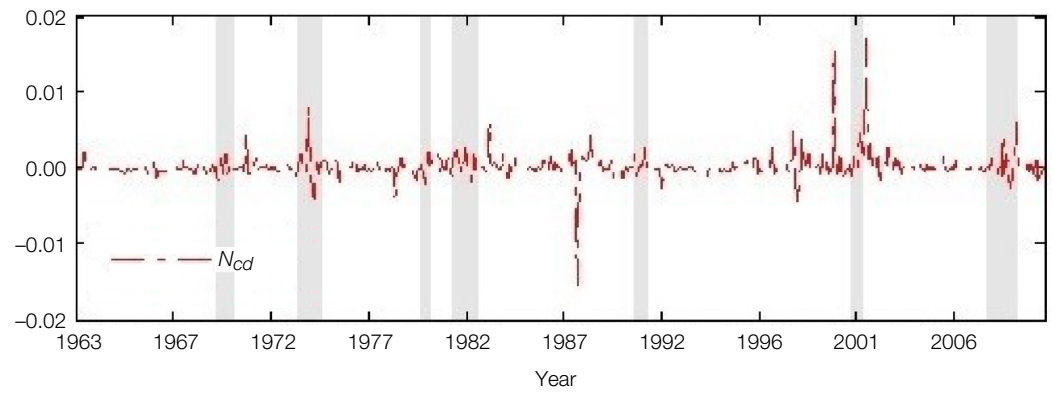




\section{Extreme Macroeconomic Environment in Covariation Recessions}

Figure 3 illustrates the extreme macroeconomic environment during the two recessions in which covariation was most negative. The shaded areas represent National Bureau of Economic Research (NBER) recessions, and the outlined shaded areas represent the two covariation recessions. The graphs plot annual market returns, real consumption growth, industrial production growth, and changes in the unemployment rate. The sample period is from July 1963 to Dec. 2010.
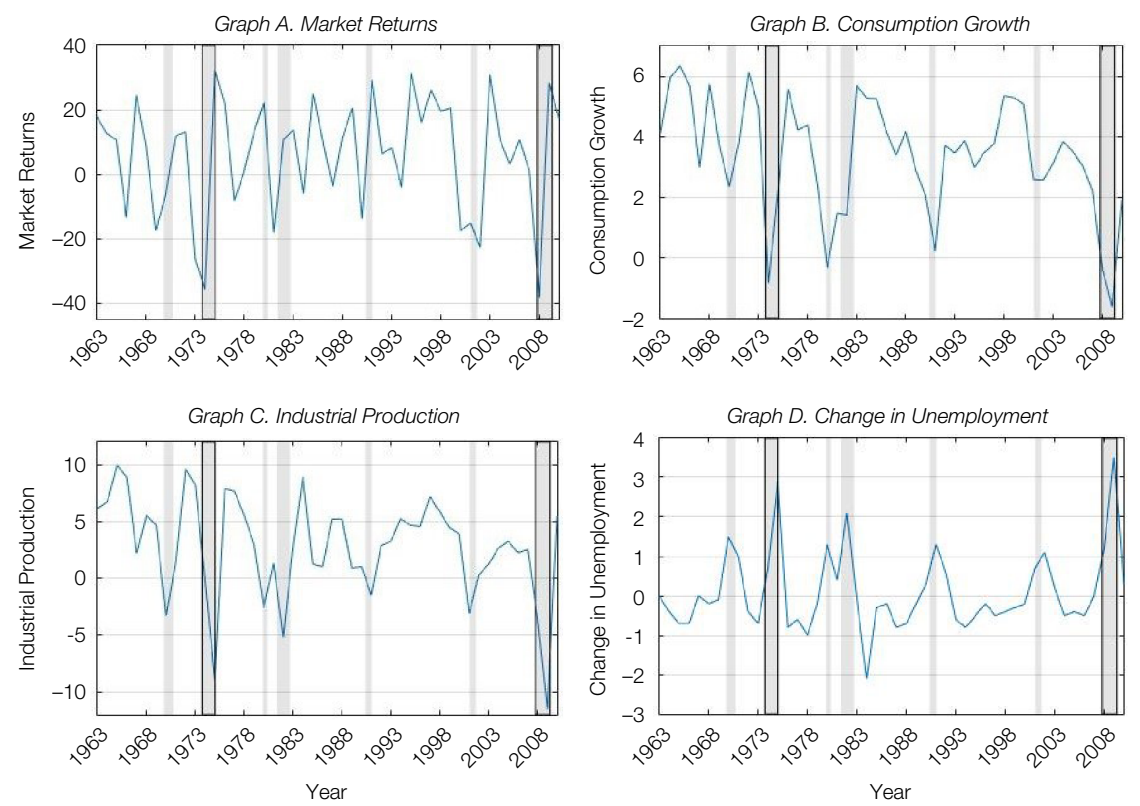

the 1973-1975 recession and the recent financial crisis of 2008-2009. We characterize these two recessions as "covariation recessions," that is, recessions in which the covariance between the cash-flow news and discount-rate news is notably negative. Figure 3 provides evidence that suggests these two recessions were two of the most challenging macroeconomic environments in our sample. The results depicted in this figure show that these two covariation recessions encompass not only the years with the largest losses in equity markets but also those with the largest declines in real consumption expenditure, the steepest drops in industrial production, and the steepest increases in unemployment rates. ${ }^{8}$ Notably, these results cannot be attributed to the mechanical relation between these indicators and our covariation estimates because none of these indicators is used in our estimation procedure.

Figure 3 provides some useful insights in regard to the nature of the covariation risk that investors wish to hedge against in our model. From the perspective of our model, the increase in discount rates during these recessions was not simply the result of better future investment opportunities that would lead to an increase in future cash flows (due to the positive covariance between these two components). Instead, increased precautionary savings against future declines in wealth

\footnotetext{
${ }^{8}$ The data used in this analysis were obtained from the Federal Reserve Economic Data (FRED) database.
} 
in these times amplifies the bad news to future cash flows, leading to larger drops in consumption. Although, similar to other asset pricing studies (e.g., Campbell and Vuolteenaho (2004), Bansal et al. (2014)), we do not model the production side of the economy, these results offer some support that such large drops in consumption are likely to lead to a steep reduction in production and employment by firms, thereby resulting in further declines in future cash flows and in investments in new projects. ${ }^{9}$

\section{Empirical Results}

\section{A. Calibration of Model-Implied Risk Premia}

We commence our analysis with a simple calibration exercise (untabulated for brevity). Specifically, we evaluate the magnitudes of the risk premia attributable to various sources of risk in our model for different values of the representative investor's risk aversion $(\gamma=1,5,10)$. For the ICAPM-CRD-MGARCH, we set the persistence parameter $\chi$ to $62.5 .^{10}$ The relative contribution of various sources of risk will be driven by these parameter values, the model-implied risk premium coefficients as per equations (10) and (11), and the exposure of the portfolio under consideration to these risks.

We find that the market portfolio is exposed to both variation and covariation risks. However, the magnitude of their impact on the risk premium of the aggregate market is smaller compared with the first-moment news terms. We also examine the relative importance of calibrated risk premia in explaining the size and value premia. We find that our model attributes the largest share of the value premium (highest minus lowest decile book-to-market portfolio) to cash-flow risk. We also find that our model attributes the largest share of the size premium (lowest minus highest decile market-capitalization portfolio) to covariation risk. The latter finding provides preliminary evidence that covariation risk is an important determinant of risk premia in the cross section of stocks. Further, this analysis also highlights the difference between our two models: ICAPM-CRD and ICAPM-CRD-MGARCH. Although the risk exposures of equity portfolios are identical in both models, the (untabulated) model-implied risk premia are substantially larger for the ICAPM-CRD-MGARCH, highlighting the importance of accounting for the volatility risk within the framework of coskewness risk decomposition.

\footnotetext{
${ }^{9}$ As discussed earlier, our model suggests that declines in the covariance between the cash-flow and discount-rate news are associated with higher macroeconomic uncertainty. In this context, the particularly challenging macroeconomic environments observed in covariation recessions could also be driven by the impact of macroeconomic uncertainty on firms' investment decisions (Foote, Hurst, and Leahy (2000), Bloom (2014)). These studies suggest that high macroeconomic uncertainty increases the value of the option to wait, thereby making firms more cautious about actions such as investment and hiring.

${ }^{10}$ This parameter is estimated from the long-run impact of a 1-period revision in the variance for a univariate GARCH process for market volatility $(\chi=1 /(1-(a+b)))$, where $a$ and $b$ denote ARCH and GARCH parameters, respectively. We obtain the values for these parameters from a GARCH $(1,1)$ model fitted to the time series of market returns.
} 


\section{B. Estimating Risk Premia Using Portfolios of Stocks}

In this section, we estimate and test our model using a cross section of portfolio returns. Our baseline set of test portfolios includes 25 portfolios sorted by firm size and firm book-to-market ratio and 25 portfolios sorted by firm size and past stock performance (momentum). Size/book-to-market-sorted portfolios have been used as test assets in previous studies (e.g., Hodrick and Zhang (2001), Campbell and Vuolteenaho (2004), and Hahn and Lee (2006)). We also include size/momentum-sorted portfolios because the momentum factor poses a particular challenge for asset pricing models (Jegadeesh and Titman (2005), Lewellen, Nagel, and Shanken (2010)). Of particular relevance to our setting, prior research suggests that some of the size, book-to-market ratio, and momentum effects in stock returns can be attributed to the coskewness risk (Harvey and Siddique (2000), Barone-Adesi et al. (2004)). Because our model focuses on the decomposition of coskewness risk, using portfolios sorted by these attributes as test assets allows us to assess incremental improvements in model performance that stem from the coskewness decomposition. For each of these portfolios, we estimate its monthly excess return as the difference between the gross monthly return and the yield on the 1-month Treasury bill. All data were obtained from Kenneth French's data library (http://mba.tuck.dartmouth.edu/pages/faculty/ken.french/data_library .html) and the Center for Research in Security Prices (CRSP). The sample period is from July 1963 to Dec. 2010. ${ }^{11}$

\section{Risk Exposures of Test Portfolios}

In this section, we examine the risk exposures (betas) of our baseline test portfolios. Following Campbell and Vuolteenaho (2004), we define the cash-flow beta $\left(\beta_{c}\right)$ as $\operatorname{cov}\left(r_{i}, N_{c}\right) / \operatorname{var}\left(r_{m}\right)$ and the discount-rate beta $\left(\beta_{d}\right)$ as $\operatorname{cov}\left(r_{i},-N_{d}\right) / \operatorname{var}\left(r_{m}\right)$. Here, $r_{i}$ is the return on the test portfolio $i$, and $r_{m}$ is the unexpected return on the market portfolio, so $\beta_{c}$ and $\beta_{d}$ sum up to the CAPM beta. Similarly, we define the cash-flow-variation beta $\left(\beta_{c c}\right)$ and the discount-ratevariation beta $\left(\beta_{d d}\right)$ as $\operatorname{cov}\left(r_{i}, N_{c c}\right) / \operatorname{var}\left(r_{m}\right)$ and $\operatorname{cov}\left(r_{i}, N_{d d}\right) / \operatorname{var}\left(r_{m}\right)$, respectively, and the covariation beta $\left(\beta_{c d}\right)$ as $\operatorname{cov}\left(r_{i}, N_{c d}\right) / \operatorname{var}\left(r_{m}\right)$, so $\beta_{c c}, \beta_{d d}$, and $\beta_{c d}$ represent the components of the coskewness beta. Hence, for a given test portfolio and a given news term, beta can be expressed as the product of the following two items: i) the univariate regression slope of the test portfolio returns on the time series of the news term and ii) the ratio of the variance of the news term to the variance of unexpected market returns. Consistent with this, we estimate the cash-flow (discount-rate) beta as the slope from the univariate regression of test portfolio returns on the time series of the cash-flow (discount-rate) news term times the

\footnotetext{
${ }^{11}$ The observed patterns in test portfolio returns in our sample (untabulated here for brevity) are consistent with prior research (e.g., Jegadeesh and Titman (1993), Hodrick and Zhang (2001), Hahn and Lee (2006), and Fama and French (2015)). Specifically, small-cap stocks have higher average returns compared with large-cap stocks, and stocks with a high book-to-market ratio (value stocks) have higher average returns compared with stocks with a low book-to-market ratio (growth stocks). In addition, stocks with good past performance have higher average returns compared with stocks with poor past performance, and the effect is more pronounced for small-cap stocks.
} 
ratio of cash-flow news (discount-rate news) variance to unexpected market return variance (Campbell and Vuolteenaho (2004), Campbell et al. (2018)).

Although a similar estimation approach can be applied to the second-moment news terms, the betas for the second-moment news terms estimated using this method are expected to have low precision. This is because a substantial portion of the time-series fluctuations in the test portfolio returns is driven by the fluctuations in market returns, reflecting the impact of the first-moment news terms. Consequently, the univariate regression slopes of the second-moment news terms will have large standard errors. Hence, to facilitate statistical inferences about beta estimates for the second-moment news terms, we adopt the following 2-step approach: In the first step, we orthogonalize the market returns with respect to the second-moment news term for which we want to estimate the portfolio beta. In the second step, we regress test portfolio returns on that particular second-moment news term and the orthogonalized market returns and use the slope of the secondmoment news term as the estimate of beta. ${ }^{12}$

The results are presented in Table 2, where Panel A reports the estimates of the betas for the size/book-to-market-sorted portfolios, and Panel B reports the estimates of the betas for the size/momentum-sorted portfolios. The estimates of Panel A are organized in a square matrix with small-cap (large-cap) stocks on the top (bottom) and high-book-to-market (low-book-to-market) stocks on the left (right). In Panel B, the estimates for the small-cap (large-cap) stocks are reported on the top (bottom), and the estimates for the stocks with poor (good) past performance are reported on the left (right). For each quintile (size, book-to-market ratio, past performance), we report the differences between the estimated betas for the extreme portfolios. The corresponding standard errors adjusted for heteroscedasticity and serial correlation are reported in parentheses.

First consider the estimates of betas for the size/book-to-market-sorted portfolios. The observed patterns in the estimates of the cash-flow betas and discountrate betas are largely consistent with those reported by Campbell and Vuolteenaho (2004). Specifically, the cash-flow betas are significantly larger for value stocks compared with growth stocks. In addition, the discount-rate betas are significantly larger for small-cap stocks compared with large-cap stocks. The estimates of the cash-flow-variation betas are negative and significant, and so are the estimates of the discount-rate-variation betas, suggesting that, on average, stocks exhibit significant exposure to both cash-flow-variation and discount-rate-variation risks. The estimates of the covariation risk betas are positive and statistically significant, suggesting that equity portfolios exhibit significant exposure to covariation

\footnotetext{
${ }^{12}$ This modification of the univariate regression approach serves two purposes: i) It preserves the theoretical interpretation of the estimates of the second-moment news term betas as the components of the coskewness risk decomposition and ii) it allows more accurate statistical inferences about the estimates of the second-moment news term betas because the portion of the variance of test portfolio returns driven by the fluctuations in market returns is "washed out." For completeness, we reestimate second-order term betas using a standard univariate regression method. Consistent with our expectations, this approach results in larger standard errors of individual portfolio betas but has no material impact on our results for the differences in betas across the extreme portfolios, which is the main focus of this analysis.
} 
risk. Further, the covariation risk betas are significantly larger for small-cap stocks compared with large-cap stocks.

Now consider the estimates of betas for the size/momentum-sorted portfolios. The cash-flow betas appear to be slightly lower for stocks with high past returns compared with stocks with poor past performance. The difference, however, is not significant for most of the categories. The discount-rate betas display a distinct U-shape, being the largest for stocks with either poor or high past performance. This observation suggests that portfolios comprised of stocks with poor or high past performance (i.e., stocks that experienced large absolute returns in

\section{TABLE 2}

\section{Risk Exposures of Test Portfolios}

In Table 2, we report the betas of the portfolios sorted based on market capitalization (size) and book-to-market ratio for the sample period from July 1963 to Dec. 2010. The betas are estimated as $\operatorname{cov}\left(r_{i}, N_{(.)}\right) / \operatorname{var}\left(r_{m}\right)$, where $N_{(.)}$represents the cash-flow news $\left(N_{c}\right)$ for $\beta_{c}$, the discount-rate news $\left(-N_{d}\right)$ for $\beta_{d}$, the cash-flow-variation news $\left(N_{c c}\right)$ for $\beta_{c c}$, the discount-rate-variation news $\left(N_{d d}\right)$ for $\beta_{d d}$, and the covariation news $\left(N_{c c}\right)$ for $\beta_{c d}$. The values for the latter three betas were multiplied by 100 for ease of exposition. The variable $r_{i}$ is the excess return on the portfolio, and $r_{m}$ is the unexpected excess market return. Standard errors (in parentheses) are adjusted for heteroscedasticity and serial correlation. The "Diff." columns report the differences between the estimates of the extreme portfolio betas and the corresponding standard errors (in parentheses). Bold denotes differences that are significant at a 2-sided 5\% level or stronger. In Panel A, we report the betas of the 25 size and book-to-market portfolios. Here, "Growth" ("Value") denotes stocks with the lowest (largest) book-to-market ratio, and "Small" ("Large") denotes stocks with the lowest (largest) market capitalization. In Panel B, we report the betas of the 25 size and past-performance (momentum) portfolios. Here, "Small" ("Large") denotes stocks with the lowest (largest) market capitalization, and "Losers" ("Winners") denotes stocks with the lowest (highest) returns from month $t-12$ to month $t-2$.

Panel A. Size/Book-to-Market-Sorted Portfolios

\begin{tabular}{|c|c|c|c|c|c|c|c|c|c|c|c|c|}
\hline & \multicolumn{2}{|c|}{ Growth } & \multicolumn{2}{|c|}{2} & \multicolumn{2}{|c|}{3} & \multicolumn{2}{|c|}{4} & \multicolumn{2}{|c|}{ Value } & \multicolumn{2}{|c|}{ Diff. } \\
\hline $\begin{array}{l}\beta_{c} \\
\text { Small } \\
2 \\
3 \\
4 \\
\text { Large }\end{array}$ & $\begin{array}{l}0.12 \\
0.13 \\
0.13 \\
0.14 \\
0.14\end{array}$ & $\begin{array}{l}(0.06) \\
(0.05) \\
(0.05) \\
(0.04) \\
(0.03)\end{array}$ & $\begin{array}{l}0.14 \\
0.16 \\
0.18 \\
0.19 \\
0.18\end{array}$ & $\begin{array}{l}(0.05) \\
(0.04) \\
(0.03) \\
(0.03) \\
(0.03)\end{array}$ & $\begin{array}{l}0.16 \\
0.17 \\
0.19 \\
0.20 \\
0.18\end{array}$ & $\begin{array}{l}(0.04) \\
(0.03) \\
(0.03) \\
(0.03) \\
(0.03)\end{array}$ & $\begin{array}{l}0.17 \\
0.19 \\
0.20 \\
0.21 \\
0.21\end{array}$ & $\begin{array}{l}(0.04) \\
(0.03) \\
(0.03) \\
(0.03) \\
(0.03)\end{array}$ & $\begin{array}{l}0.20 \\
0.22 \\
0.22 \\
0.24 \\
0.21\end{array}$ & $\begin{array}{l}(0.04) \\
(0.04) \\
(0.03) \\
(0.03) \\
(0.03)\end{array}$ & $\begin{array}{l}0.08 \\
0.09 \\
0.09 \\
0.10 \\
0.07\end{array}$ & $\begin{array}{l}(0.03) \\
(0.03) \\
(0.03) \\
(0.03) \\
(0.02)\end{array}$ \\
\hline Diff. & 0.02 & $(0.04)$ & 0.04 & $(0.04)$ & 0.02 & $(0.03)$ & 0.04 & $(0.04)$ & 0.01 & $(0.03)$ & & \\
\hline $\begin{array}{l}\beta_{d} \\
\text { Small } \\
2 \\
3 \\
4 \\
\text { Large }\end{array}$ & $\begin{array}{l}1.25 \\
1.22 \\
1.16 \\
1.05 \\
0.83\end{array}$ & $\begin{array}{l}(0.06) \\
(0.05) \\
(0.04) \\
(0.04) \\
(0.04)\end{array}$ & $\begin{array}{l}1.03 \\
0.96 \\
0.89 \\
0.86 \\
0.74\end{array}$ & $\begin{array}{l}(0.06) \\
(0.05) \\
(0.05) \\
(0.05) \\
(0.05)\end{array}$ & $\begin{array}{l}0.88 \\
0.84 \\
0.77 \\
0.79 \\
0.68\end{array}$ & $\begin{array}{l}(0.05) \\
(0.05) \\
(0.05) \\
(0.06) \\
(0.05)\end{array}$ & $\begin{array}{l}0.80 \\
0.78 \\
0.71 \\
0.72 \\
0.60\end{array}$ & $\begin{array}{l}(0.05) \\
(0.05) \\
(0.05) \\
(0.05) \\
(0.05)\end{array}$ & $\begin{array}{l}0.82 \\
0.84 \\
0.76 \\
0.76 \\
0.64\end{array}$ & $\begin{array}{l}(0.06) \\
(0.06) \\
(0.06) \\
(0.06) \\
(0.06)\end{array}$ & $\begin{array}{l}-0.43 \\
-0.38 \\
-0.39 \\
-0.29 \\
-0.19\end{array}$ & $\begin{array}{l}(0.06) \\
(0.05) \\
(0.06) \\
(0.06) \\
(0.06)\end{array}$ \\
\hline Diff. & -0.42 & $(0.07)$ & -0.29 & $(0.07)$ & -0.20 & $(0.06)$ & -0.20 & $(0.06)$ & -0.18 & $(0.06)$ & & \\
\hline $\begin{array}{l}\beta_{c c} \\
\text { Small } \\
2 \\
3 \\
4 \\
\text { Large }\end{array}$ & $\begin{array}{l}-0.69 \\
-0.68 \\
-0.64 \\
-0.48 \\
-0.36\end{array}$ & $\begin{array}{l}(0.19) \\
(0.10) \\
(0.08) \\
(0.06) \\
(0.04)\end{array}$ & $\begin{array}{l}-0.59 \\
-0.62 \\
-0.64 \\
-0.59 \\
-0.50\end{array}$ & $\begin{array}{l}(0.16) \\
(0.08) \\
(0.07) \\
(0.05) \\
(0.08)\end{array}$ & $\begin{array}{l}-0.59 \\
-0.59 \\
-0.55 \\
-0.59 \\
-0.54\end{array}$ & $\begin{array}{l}(0.12) \\
(0.09) \\
(0.06) \\
(0.10) \\
(0.07)\end{array}$ & $\begin{array}{l}-0.55 \\
-0.62 \\
-0.56 \\
-0.53 \\
-0.54\end{array}$ & $\begin{array}{l}(0.14) \\
(0.09) \\
(0.08) \\
(0.09) \\
(0.10)\end{array}$ & $\begin{array}{l}-0.66 \\
-0.70 \\
-0.58 \\
-0.75 \\
-0.65\end{array}$ & $\begin{array}{l}(0.15) \\
(0.12) \\
(0.11) \\
(0.11) \\
(0.09)\end{array}$ & $\begin{array}{r}0.03 \\
-0.02 \\
0.06 \\
-0.27 \\
-0.29\end{array}$ & $\begin{array}{l}(0.22) \\
(0.16) \\
(0.15) \\
(0.15) \\
(0.11)\end{array}$ \\
\hline Diff. & 0.33 & $(0.18)$ & 0.09 & $(0.22)$ & 0.05 & $(0.17)$ & 0.01 & $(0.19)$ & 0.01 & $(0.17)$ & & \\
\hline $\begin{array}{l}\beta_{d d} \\
\text { Small } \\
2 \\
3 \\
4 \\
\text { Large }\end{array}$ & $\begin{array}{l}-2.71 \\
-2.55 \\
-2.35 \\
-2.07 \\
-1.59\end{array}$ & $\begin{array}{l}(0.60) \\
(0.31) \\
(0.27) \\
(0.19) \\
(0.14)\end{array}$ & $\begin{array}{l}-2.26 \\
-2.52 \\
-2.40 \\
-2.45 \\
-1.94\end{array}$ & $\begin{array}{l}(0.55) \\
(0.25) \\
(0.23) \\
(0.16) \\
(0.28)\end{array}$ & $\begin{array}{l}-2.09 \\
-2.41 \\
-2.38 \\
-2.56 \\
-1.88\end{array}$ & $\begin{array}{l}(0.37) \\
(0.24) \\
(0.22) \\
(0.30) \\
(0.27)\end{array}$ & $\begin{array}{l}-1.87 \\
-2.34 \\
-2.21 \\
-2.05 \\
-1.68\end{array}$ & $\begin{array}{l}(0.42) \\
(0.22) \\
(0.19) \\
(0.26) \\
(0.35)\end{array}$ & $\begin{array}{l}-2.64 \\
-2.42 \\
-2.41 \\
-2.45 \\
-2.29\end{array}$ & $\begin{array}{l}(0.31) \\
(0.27) \\
(0.27) \\
(0.31) \\
(0.32)\end{array}$ & $\begin{array}{r}0.07 \\
0.13 \\
-0.06 \\
-0.38 \\
-0.70\end{array}$ & $\begin{array}{l}(0.52) \\
(0.33) \\
(0.39) \\
(0.44) \\
(0.35)\end{array}$ \\
\hline Diff. & 1.12 & $(0.64)$ & 0.32 & $(0.76)$ & 0.21 & $(0.56)$ & 0.19 & $(0.70)$ & 0.35 & $(0.51)$ & & \\
\hline $\begin{array}{l}\beta_{c d} \\
\text { Small } \\
2 \\
3 \\
4 \\
\text { Large }\end{array}$ & $\begin{array}{l}1.00 \\
0.82 \\
0.69 \\
0.55 \\
0.35\end{array}$ & $\begin{array}{l}(0.32) \\
(0.17) \\
(0.14) \\
(0.09) \\
(0.05)\end{array}$ & $\begin{array}{l}1.01 \\
0.74 \\
0.56 \\
0.49 \\
0.29\end{array}$ & $\begin{array}{l}(0.24) \\
(0.10) \\
(0.11) \\
(0.07) \\
(0.14)\end{array}$ & $\begin{array}{l}0.89 \\
0.61 \\
0.43 \\
0.37 \\
0.21\end{array}$ & $\begin{array}{l}(0.14) \\
(0.08) \\
(0.09) \\
(0.15) \\
(0.14)\end{array}$ & $\begin{array}{l}0.89 \\
0.53 \\
0.33 \\
0.27 \\
0.11\end{array}$ & $\begin{array}{l}(0.13) \\
(0.08) \\
(0.11) \\
(0.12) \\
(0.14)\end{array}$ & $\begin{array}{l}0.72 \\
0.68 \\
0.53 \\
0.24 \\
0.09\end{array}$ & $\begin{array}{l}(0.09) \\
(0.10) \\
(0.12) \\
(0.16) \\
(0.17)\end{array}$ & $\begin{array}{l}-0.28 \\
-0.14 \\
-0.16 \\
-0.31 \\
-0.26\end{array}$ & $\begin{array}{l}(0.33) \\
(0.19) \\
(0.23) \\
(0.22) \\
(0.21)\end{array}$ \\
\hline Diff. & -0.65 & $(0.32)$ & -0.72 & $(0.36)$ & -0.68 & $(0.26)$ & -0.78 & $(0.25)$ & -0.63 & $\begin{array}{l}\text { (0.19) } \\
\text { (contin }\end{array}$ & a on ? & \\
\hline
\end{tabular}


TABLE 2 (continued)

Risk Exposures of Test Portfolios

\begin{tabular}{|c|c|c|c|c|c|c|c|c|c|c|c|c|}
\hline$\beta_{c}$ & \multicolumn{2}{|c|}{ Losers } & \multicolumn{2}{|c|}{2} & \multicolumn{2}{|c|}{3} & \multicolumn{2}{|c|}{4} & \multicolumn{2}{|c|}{ Winners } & \multicolumn{2}{|c|}{ Diff. } \\
\hline $\begin{array}{l}\text { Small } \\
2 \\
3 \\
4 \\
\text { Large }\end{array}$ & $\begin{array}{l}0.21 \\
0.21 \\
0.22 \\
0.23 \\
0.25\end{array}$ & $\begin{array}{l}(0.05) \\
(0.05) \\
(0.05) \\
(0.05) \\
(0.04)\end{array}$ & $\begin{array}{l}0.18 \\
0.18 \\
0.19 \\
0.22 \\
0.18\end{array}$ & $\begin{array}{l}(0.04) \\
(0.04) \\
(0.03) \\
(0.03) \\
(0.03)\end{array}$ & $\begin{array}{l}0.17 \\
0.18 \\
0.18 \\
0.19 \\
0.17\end{array}$ & $\begin{array}{l}(0.03) \\
(0.04) \\
(0.03) \\
(0.03) \\
(0.03)\end{array}$ & $\begin{array}{l}0.17 \\
0.18 \\
0.18 \\
0.19 \\
0.17\end{array}$ & $\begin{array}{l}(0.03) \\
(0.04) \\
(0.03) \\
(0.03) \\
(0.02)\end{array}$ & $\begin{array}{l}0.16 \\
0.16 \\
0.16 \\
0.17 \\
0.15\end{array}$ & $\begin{array}{l}(0.04) \\
(0.05) \\
(0.04) \\
(0.04) \\
(0.03)\end{array}$ & $\begin{array}{l}-0.05 \\
-0.05 \\
-0.06 \\
-0.06 \\
-0.09\end{array}$ & $\begin{array}{l}(0.03) \\
(0.04) \\
(0.04) \\
(0.04) \\
(0.04)\end{array}$ \\
\hline Diff. & 0.04 & $(0.03)$ & 0.00 & $(0.03)$ & 0.00 & $(0.02)$ & 0.00 & $(0.02)$ & -0.01 & $(0.03)$ & & \\
\hline $\begin{array}{l}\beta_{d} \\
\text { Small } \\
2 \\
3 \\
4 \\
\text { Large }\end{array}$ & $\begin{array}{l}1.08 \\
1.18 \\
1.08 \\
1.04 \\
0.94\end{array}$ & $\begin{array}{l}(0.07) \\
(0.07) \\
(0.07) \\
(0.08) \\
(0.07)\end{array}$ & $\begin{array}{l}0.83 \\
0.88 \\
0.85 \\
0.84 \\
0.73\end{array}$ & $\begin{array}{l}(0.06) \\
(0.06) \\
(0.05) \\
(0.06) \\
(0.06)\end{array}$ & $\begin{array}{l}0.77 \\
0.80 \\
0.79 \\
0.77 \\
0.71\end{array}$ & $\begin{array}{l}(0.06) \\
(0.05) \\
(0.05) \\
(0.05) \\
(0.04)\end{array}$ & $\begin{array}{l}0.79 \\
0.83 \\
0.79 \\
0.78 \\
0.70\end{array}$ & $\begin{array}{l}(0.05) \\
(0.05) \\
(0.05) \\
(0.05) \\
(0.05)\end{array}$ & $\begin{array}{l}1.00 \\
1.09 \\
1.03 \\
0.96 \\
0.86\end{array}$ & $\begin{array}{l}(0.07) \\
(0.06) \\
(0.06) \\
(0.05) \\
(0.05)\end{array}$ & $\begin{array}{l}-0.08 \\
-0.08 \\
-0.05 \\
-0.08 \\
-0.08\end{array}$ & $\begin{array}{l}(0.08) \\
(0.09) \\
(0.09) \\
(0.10) \\
(0.10)\end{array}$ \\
\hline Diff. & -0.13 & $(0.05)$ & -0.09 & $(0.05)$ & -0.06 & $(0.04)$ & -0.09 & $(0.04)$ & -0.14 & $(0.05)$ & & \\
\hline $\begin{array}{l}\beta_{c c} \\
\text { Small } \\
2 \\
3 \\
4 \\
\text { Large }\end{array}$ & $\begin{array}{l}-0.92 \\
-0.91 \\
-0.89 \\
-0.84 \\
-0.70\end{array}$ & $\begin{array}{l}(0.13) \\
(0.11) \\
(0.12) \\
(0.18) \\
(0.16)\end{array}$ & $\begin{array}{l}-0.73 \\
-0.72 \\
-0.65 \\
-0.69 \\
-0.53\end{array}$ & $\begin{array}{l}(0.12) \\
(0.09) \\
(0.06) \\
(0.11) \\
(0.11)\end{array}$ & $\begin{array}{l}-0.69 \\
-0.65 \\
-0.60 \\
-0.59 \\
-0.49\end{array}$ & $\begin{array}{l}(0.11) \\
(0.07) \\
(0.07) \\
(0.09) \\
(0.04)\end{array}$ & $\begin{array}{l}-0.64 \\
-0.63 \\
-0.64 \\
-0.56 \\
-0.38\end{array}$ & $\begin{array}{l}(0.12) \\
(0.09) \\
(0.09) \\
(0.07) \\
(0.06)\end{array}$ & $\begin{array}{l}-0.62 \\
-0.46 \\
-0.52 \\
-0.50 \\
-0.41\end{array}$ & $\begin{array}{l}(0.14) \\
(0.17) \\
(0.11) \\
(0.08) \\
(0.06)\end{array}$ & $\begin{array}{l}0.30 \\
0.45 \\
0.37 \\
0.34 \\
0.29\end{array}$ & $\begin{array}{l}(0.16) \\
(0.21) \\
(0.20) \\
(0.24) \\
(0.21)\end{array}$ \\
\hline Diff. & 0.22 & $(0.14)$ & 0.20 & $(0.15)$ & 0.20 & $(0.11)$ & 0.26 & $(0.12)$ & 0.21 & $(0.15)$ & & \\
\hline $\begin{array}{l}\beta_{d d} \\
\text { Small } \\
2 \\
3 \\
4 \\
\text { Large }\end{array}$ & $\begin{array}{l}-3.19 \\
-3.05 \\
-2.39 \\
-2.41 \\
-2.29\end{array}$ & $\begin{array}{l}(0.29) \\
(0.29) \\
(0.38) \\
(0.55) \\
(0.56)\end{array}$ & $\begin{array}{l}-2.71 \\
-2.62 \\
-2.47 \\
-2.47 \\
-1.86\end{array}$ & $\begin{array}{l}(0.23) \\
(0.21) \\
(0.23) \\
(0.31) \\
(0.39)\end{array}$ & $\begin{array}{l}-2.57 \\
-2.42 \\
-2.39 \\
-2.32 \\
-1.77\end{array}$ & $\begin{array}{l}(0.26) \\
(0.22) \\
(0.18) \\
(0.23) \\
(0.18)\end{array}$ & $\begin{array}{l}-2.54 \\
-2.38 \\
-2.42 \\
-2.34 \\
-1.62\end{array}$ & $\begin{array}{l}(0.34) \\
(0.30) \\
(0.28) \\
(0.19) \\
(0.17)\end{array}$ & $\begin{array}{l}-2.55 \\
-2.26 \\
-2.28 \\
-2.29 \\
-1.69\end{array}$ & $\begin{array}{l}(0.47) \\
(0.59) \\
(0.37) \\
(0.30) \\
(0.21)\end{array}$ & $\begin{array}{l}0.64 \\
0.79 \\
0.12 \\
0.12 \\
0.60\end{array}$ & $\begin{array}{l}(0.55) \\
(0.69) \\
(0.68) \\
(0.76) \\
(0.73)\end{array}$ \\
\hline Diff. & 0.89 & $(0.51)$ & 0.85 & $(0.48)$ & 0.79 & $(0.32)$ & 0.92 & $(0.37)$ & 0.86 & $(0.39)$ & & \\
\hline $\begin{array}{l}\beta_{c d} \\
\text { Small } \\
2 \\
3\end{array}$ & $\begin{array}{l}0.54 \\
0.48 \\
0.25 \\
0.09 \\
0.07\end{array}$ & $\begin{array}{l}(0.12) \\
(0.13) \\
(0.16) \\
(0.23) \\
(0.22)\end{array}$ & $\begin{array}{l}0.56 \\
0.50 \\
0.34 \\
0.23 \\
0.02\end{array}$ & $\begin{array}{l}(0.10) \\
(0.08) \\
(0.09) \\
(0.15) \\
(0.11)\end{array}$ & $\begin{array}{l}0.59 \\
0.54 \\
0.48 \\
0.35 \\
0.35\end{array}$ & $\begin{array}{l}(0.11) \\
(0.10) \\
(0.09) \\
(0.14) \\
(0.05)\end{array}$ & $\begin{array}{l}0.71 \\
0.67 \\
0.56 \\
0.35 \\
0.33\end{array}$ & $\begin{array}{l}(0.10) \\
(0.09) \\
(0.13) \\
(0.11) \\
(0.08)\end{array}$ & $\begin{array}{l}0.99 \\
1.05 \\
0.85 \\
0.72 \\
0.51\end{array}$ & $\begin{array}{l}(0.13) \\
(0.25) \\
(0.11) \\
(0.08) \\
(0.07)\end{array}$ & $\begin{array}{l}0.45 \\
0.57 \\
0.59 \\
0.63 \\
0.44\end{array}$ & $\begin{array}{l}(0.17) \\
(0.23) \\
(0.20) \\
(0.26) \\
(0.27)\end{array}$ \\
\hline Diff. & -0.47 & $(0.18)$ & -0.54 & $(0.13)$ & -0.23 & $(0.10)$ & -0.38 & $(0.11)$ & -0.48 & $(0.11)$ & & \\
\hline
\end{tabular}

the past) are potentially picking stocks with high sensitivity to changes in the discount rate. Importantly, the estimates of the covariation risk betas are positive and monotonically increasing when moving from stocks with poor past performance to stocks with high past performance, and the difference is also statistically significant. These results suggest that portfolios comprising of stocks with high past performance have greater exposure to covariation risk relative to the market. In addition, similar to the results reported in Panel A of Table 2, we find the estimates of covariation risk betas to be significantly larger for small-cap stocks relative to large-cap stocks.

\section{Estimation of the Risk Premia}

Having estimated the risk exposures (betas) for the test portfolios, our next step is to estimate the model risk premia. As discussed earlier, our baseline set of test portfolios includes 25 portfolios sorted by firm size and firm book-to-market ratio and 25 portfolios sorted by firm size and past stock performance (momentum). We further expand our set of test portfolios to include 32 three-way size/investment/profitability-sorted portfolios (Novy-Marx (2013), 
Fama and French (2015)). ${ }^{13}$ Hence, in total, we use 82 test portfolios. Following prior research (Campbell and Vuolteenaho (2004), Campbell et al. (2018)), we estimate the risk premia using the following cross-sectional regression:

$$
\bar{R}_{i}^{e}=g_{0}+\sum_{k=1}^{K} g_{k} \hat{\beta}_{i, k}+\varepsilon_{i},
$$

where $\bar{R}_{i}^{e}$ is the average excess portfolio return over the 1-month Treasury bill rate, $\hat{\beta}_{i, k}$ is the estimated risk exposure with respect to the $k$ th risk factor, and $g_{k}$ is the $k$ th factor risk premium. To incorporate estimation uncertainty in estimated betas, we produce standard errors with a bootstrap from 5,000 simulated realizations, following Campbell and Vuolteenaho (2004).

As discussed in Section III, we consider two versions of the model: i) the ICAPM-CRD, developed under the assumption of an IES close to 1, and ii) the ICAPM-CRD-MGARCH, developed under the assumption of the IES being greater than 1 . We compare the performance of these two models to the performance of the following models: i) the CAPM (Sharpe (1964), Lintner (1965)), ii) the 2-beta ICAPM (Campbell and Vuolteenaho (2004)), iii) the CAPM with coskewness (Kraus and Litzenberger (1976), Harvey and Siddique (2000)), iv) the 4-factor Fama-French-Carhart model (Fama and French (1993), Carhart (1997)), and v) the 5-factor Fama-French model (Fama and French (2015)).

We use the following two statistics to evaluate model performance: i) the cross-sectional adjusted $R^{2}$ and ii) the cross-sectional pricing error $(\vartheta)$. To assess the significance of the adjusted $R^{2}$ statistic, we follow Lewellen et al. (2010) and simulate the distribution of the adjusted $R^{2}$ constructed using randomly selected artificial factors correlated with the empirical factors underlying our test portfolios. Specifically, we randomly draw $6 \times 1$ vectors of weights, $w_{i}$, from the standard normal distribution, each defining a factor $P_{i}=w_{i} F+v_{i}$, where $F$ is [MKT, SMB, HML, MOM, CMA, RMW] (i.e., empirical factors that reflect the characteristics based on which our test portfolios were constructed), and $v_{i}$ is an arbitrary random variable independent of test portfolio returns. The covariance between the test portfolio $j$ returns $\left(R_{j}\right)$ and $P_{i}$ is then $g_{i}=\operatorname{cov}\left(R_{j}, F\right) w_{\mathrm{i}}$. We repeat this 5,000 times, generating up to five artificial factors at a time (depending on the number of factors in the model tested) and storing the cross-sectional adjusted- $R^{2}$ values when the test portfolios' average returns are regressed on $g_{i}$. We report the $p$-value as a proportion of the simulated adjusted- $R^{2}$ statistics that lie above the reported value of the model-adjusted $R^{2}$. The $p$-value of the adjusted- $R^{2}$ statistic has an intuitive interpretation: It informs the researcher about the probability that the reported $R^{2}$ was obtained by "chance" due to proposed model factors being correlated with the empirical factors underlying the test portfolios.

\footnotetext{
${ }^{13}$ Prior research (Novy-Marx (2013), Fama and French (2015)) documents that firms with high operating profitability (low levels of investment) have higher average equity returns compared with firms with low operating profitability firms (high levels of investment). We find similar patterns for the portfolios sorted by these attributes in our sample.
} 
We estimate the cross-sectional pricing error $\vartheta$ as

$$
\vartheta=\left(\sum_{i=1}^{N}\left(\bar{R}_{i}^{e}-\sum_{k=1}^{K} g_{k} \hat{\beta}_{i, k}\right)^{2}\right)^{0.5} .
$$

To evaluate the statistical significance of this pricing error, we use a bootstrap method (Campbell and Vuolteenaho (2004)). Specifically, for each model, we adjust the test portfolio returns to be consistent with the model (i.e., we generate the test portfolio return series under the null that the model fully explains the average portfolio returns). Next, we simulate the distribution of the pricing error under the null using a bootstrap and report the $p$-value for the pricing error as a proportion of pricing errors from the bootstrap that exceed the realized pricing error of a given model. Again, the $p$-value of the pricing error has an intuitive interpretation: It informs the researcher about the probability that the reported model pricing error is solely due to sampling issues and not due to model misspecification.

We also report the risk-aversion parameter $(\gamma)$ implied by the estimated risk premia for the 2-beta ICAPM of Campbell and Vuolteenaho (2004) and the two versions of the proposed nonlinear ICAPM. For the 2-beta ICAPM, the implied risk-aversion parameter is estimated as the ratio of the cash-flow news premium to the variance of market returns (Campbell and Vuolteenaho (2004)). To obtain the implied risk aversion for each of the two versions of the nonlinear ICAPM, we search for the set of possible parameter values that minimizes the weighted absolute distance between the estimated risk premia and their theoretical values, shown in equations (10) and (11), respectively. The weights are estimated as the inverse of the standard errors of the risk premia estimates, which allows us to take into account the precision of the risk premia estimates from our model.

We report the estimation results in Panel A of Table 3. The first tested model is the CAPM of Sharpe (1964) and Lintner (1965). We observe that the CAPM fails to explain the cross section of returns in our sample. The estimated price of market risk is not significant. The adjusted $R^{2}$ of the model is 0.04 ( $p$-value $=0.54)$, and the model pricing error is 0.108 ( $p$-value $<0.01)$. Overall, these findings are consistent with the results reported in prior research (e.g., Campbell and Vuolteenaho (2004), Hahn and Lee (2006)).

Next, we examine the performance of the 2-beta ICAPM of Campbell and Vuolteenaho (2004). The poor performance of the 2-beta ICAPM is evident: the estimated risk premia for both the cash-flow and discount-rate betas are not significant, and the implied risk-aversion coefficient is negative due to the negative sign of the cash-flow-beta risk premium. The adjusted $R^{2}$ of the model is 0.03 ( $p$-value $=0.85)$, and the model pricing error is $0.119(p$-value $<0.01)$, suggesting that the model is rejected in our sample. ${ }^{14}$

\footnotetext{
${ }^{14}$ Campbell and Vuolteenaho (2004) show that the 2-beta ICAPM performs well in explaining the size and value effects. Consistent with their findings, the (untabulated) results show that when we limit our set of test assets to size/book-to-market portfolios, the performance of the 2-beta ICAPM improves substantially. One potential explanation of the poor performance of the 2-beta model in our setting is its inability to explain the momentum effect. This conjecture is supported by the results reported in Table 2, which show that past winners and past losers have similar cash-flow and discount-rate betas.
} 
The next model under investigation is the CAPM with coskewness (Kraus and Litzenberger (1976), Harvey and Siddique (2000)). The risk premium for the coskewness beta is negative and significant, consistent with the notion that investors are willing to accept a lower rate of return on assets that hedge against coskewness risk. The adjusted $R^{2}$ of the model is 0.46 ( $p$-value $=0.08$ ). These results are in line with prior research (Harvey and Siddique (2000), BaroneAdesi et al. (2004)), which shows that some of the size-, book-to-market-, and momentum-related effects can be explained by coskewness risk. However, the

\section{TABLE 3}

Asset Pricing Tests Using Portfolios Sorted on Size/Book to Market, Size/Momentum, and Size/Profitability/Investment

In Table 3, we report the estimated regression coefficients and the associated standard errors from the Fama-MacBeth (1973) 2-step regression approach for the sample period from July 1963 to Dec. 2010 . The dependent variable, $\bar{R}_{i}^{e}$, is the average monthly excess return over the 1-month T-bill on test asset $i$. The test assets are 25 Fama-French size/bookto-market-sorted portfolios, 25 Fama-French size/momentum-sorted portfolios, and 32 Fama-French 3-way sorted portfolios, by size, investments, and profitability. Each column reports the estimated risk premia and standard errors (in parentheses) for the corresponding asset pricing model. The standard errors are adjusted for the first-step estimation uncertainty using a bootstrap approach (Campbell and Vuolteenaho (2004)). The $p$-values of the adjusted $R^{2}$ statistics were calculated using a simulation approach (Lewellen et al. (2010)). The $p$-values of the models' pricing errors were calculated using a bootstrap approach (Campbell and Vuolteenaho (2004)). ${ }^{*},{ }^{\star *}$, and ${ }^{* \star *}$ indicate significance at the $10 \%, 5 \%$, and $1 \%$ levels, respectively.

Panel A. Model Comparison

\begin{tabular}{|c|c|c|c|c|c|c|c|}
\hline Model & CAPM & $\begin{array}{l}\text { 2-Beta } \\
\text { ICAPM }\end{array}$ & $\begin{array}{c}\text { CAPM } \\
\text { with } \\
\text { Coskewness }\end{array}$ & $\begin{array}{l}\text { Nonlinear } \\
\text { ICAPM } \\
\text { (CRD- } \\
\text { MGARCH) }\end{array}$ & $\begin{array}{l}\text { Nonlinear } \\
\text { ICAPM } \\
\text { (CRD) }\end{array}$ & $\begin{array}{l}\text { Fama- } \\
\text { French- } \\
\text { Carhart }\end{array}$ & $\begin{array}{c}\text { 5-Factor } \\
\text { Fama- } \\
\text { French }\end{array}$ \\
\hline$\alpha$ & $\begin{array}{l}0.012^{* * *} \\
(0.004)\end{array}$ & $\begin{array}{l}0.013^{* *} \\
(0.006)\end{array}$ & $\begin{array}{l}0.012^{* *} \\
(0.005)\end{array}$ & $\begin{array}{c}0.003 \\
(0.005)\end{array}$ & $\begin{array}{c}0.004 \\
(0.005)\end{array}$ & $\begin{array}{l}0.006^{* *} \\
(0.003)\end{array}$ & $\begin{array}{c}0.008 \\
(0.005)\end{array}$ \\
\hline$\beta_{\mathrm{MKT}}$ & $\begin{array}{c}-0.005 \\
(0.004)\end{array}$ & & $\begin{array}{c}-0.018^{\star * *} \\
(0.006)\end{array}$ & & & $\begin{array}{r}-0.001 \\
(0.003)\end{array}$ & $\begin{array}{r}-0.004 \\
(0.005)\end{array}$ \\
\hline$\beta_{\mathrm{MKT}}^{2}$ & & & $\begin{array}{c}-0.004^{\star *} \\
(0.002)\end{array}$ & & & & \\
\hline$\beta_{c}$ & & $\begin{array}{c}-0.011 \\
(0.029)\end{array}$ & & $\begin{array}{c}0.049^{* *} \\
(0.021)\end{array}$ & $\begin{array}{c}0.051^{* *} \\
(0.022)\end{array}$ & & \\
\hline$\beta_{d}$ & & $\begin{array}{r}-0.005 \\
(0.004)\end{array}$ & & $\begin{array}{c}-0.013 \\
(0.007)\end{array}$ & $\begin{array}{c}-0.013 \\
(0.007)\end{array}$ & & \\
\hline$\beta_{C C}$ & & & & $\begin{array}{c}0.010 \\
(0.008)\end{array}$ & $\begin{array}{c}0.007 \\
(0.008)\end{array}$ & & \\
\hline$\beta_{d d}$ & & & & $\begin{array}{r}-0.002 \\
(0.002)\end{array}$ & $\begin{array}{r}-0.002 \\
(0.002)\end{array}$ & & \\
\hline$\beta_{c d}$ & & & & $\begin{array}{l}0.012^{* *} \\
(0.005)\end{array}$ & $\begin{array}{l}0.013^{* * \star} \\
(0.005)\end{array}$ & & \\
\hline$\beta_{\mathrm{SMB}}$ & & & & & & $\begin{array}{c}0.002^{*} \\
(0.001)\end{array}$ & $\begin{array}{l}0.003^{\star * \star} \\
(0.001)\end{array}$ \\
\hline$\beta_{\mathrm{HML}}$ & & & & & & $\begin{array}{l}0.005^{\star \star \star} \\
(0.001)\end{array}$ & $\begin{array}{c}0.001 \\
(0.002)\end{array}$ \\
\hline$\beta_{\mathrm{MOM}}$ & & & & & & $\begin{array}{l}0.008^{* \star \star} \\
(0.002)\end{array}$ & \\
\hline$\beta_{\mathrm{CMA}}$ & & & & & & & $\begin{array}{l}0.005^{\star * *} \\
(0.001)\end{array}$ \\
\hline$\beta_{\mathrm{RMW}}$ & & & & & & & $\begin{array}{l}0.004^{* * *} \\
(0.001)\end{array}$ \\
\hline Adjusted $R^{2}$ & 0.04 & 0.03 & 0.46 & 0.68 & 0.69 & 0.71 & 0.62 \\
\hline$p$-value (adjusted $R^{2}$ ) & 0.54 & 0.85 & 0.08 & 0.02 & 0.02 & 0.01 & 0.09 \\
\hline Pricing error $(\vartheta)$ & 0.108 & 0.119 & 0.097 & 0.033 & 0.035 & 0.052 & 0.076 \\
\hline$p$-value $(\vartheta)$ & 0.000 & 0.000 & 0.016 & 0.562 & 0.533 & 0.009 & 0.008 \\
\hline Implied $\gamma$ & N/A & -5.30 & N/A & 9.76 & 24.58 & N/A & $\mathrm{N} / \mathrm{A}$ \\
\hline
\end{tabular}


TABLE 3 (continued)

Asset Pricing Tests Using Portfolios Sorted on Size/Book to Market, Size/Momentum, and Size/Profitability/Investment

Panel B. Sensitivity Tests of Nonlinear ICAPM Using Alternate Specifications

Nonlinear ICAPM (CRD-MGARCH)

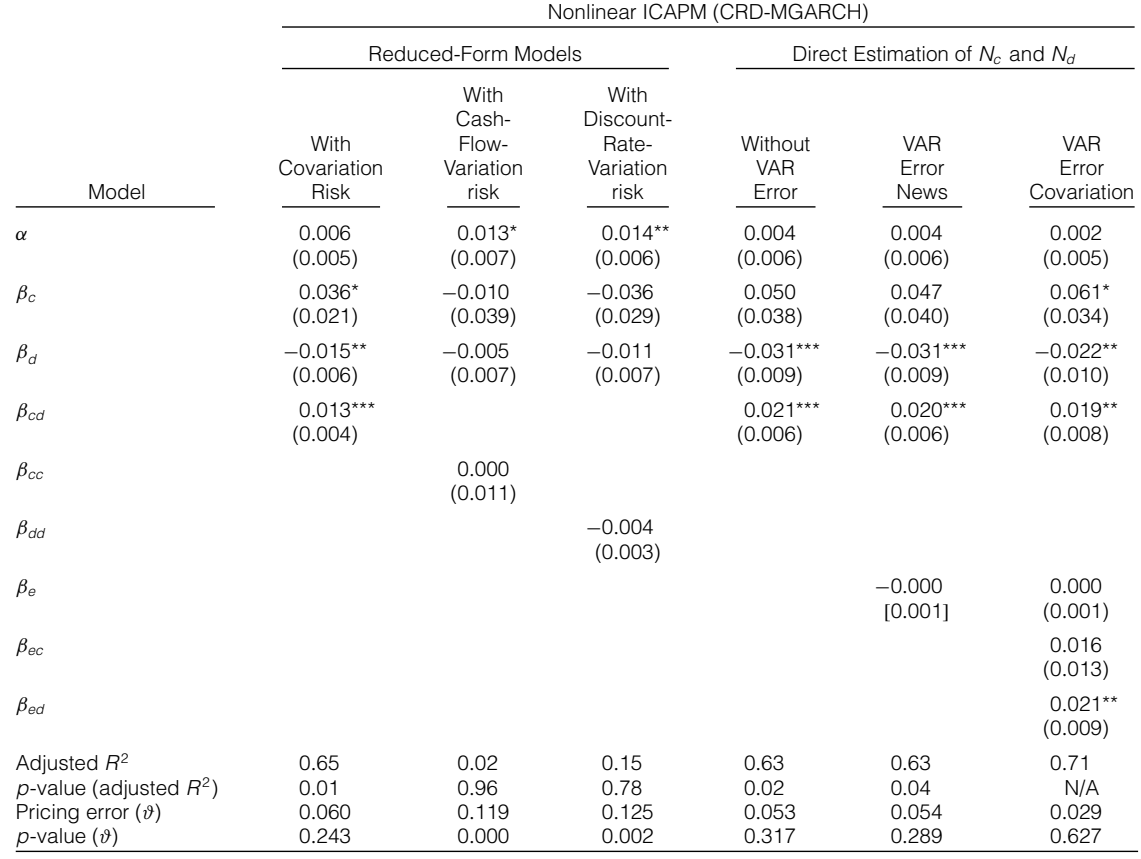

model pricing error is statistically significant ( $p$-value $<0.02$ ), suggesting that the model is rejected in our sample.

Next, we examine the performance of the ICAPM-CRD-MGARCH. The estimated risk premium for the cash-flow beta is positive and statistically significant, and so is the estimated risk premium for covariation risk. The estimates of the cash-flow-variation and discount-rate-variation risk premia are both statistically insignificant, as are the risk premia for the discount-rate beta. ${ }^{15}$ The adjusted $R^{2}$ of the model is 0.68 ( $p$-value $=0.02$ ), and the model is not rejected based on its

\footnotetext{
${ }^{15}$ Empirically, a necessary condition for an asset pricing factor to explain the cross section of expected returns (and, thus, to carry a positive and significant risk premium) is that the betas of test portfolios with respect to that particular factor should exhibit cross-sectional variation in a manner that is consistent with the spreads in the test portfolio average returns (e.g., Cochrane (2011)). In this context, a statistically significant covariation-risk premium is consistent with the patterns in covariation-risk betas reported in Table 2: Covariation-risk betas are significantly larger for small-cap stocks versus large-cap stocks, and they are significantly larger for past-winner stocks versus past-loser stocks. In contrast, as Table 2 shows, we find no such evidence for either cash-flow-variation or discount-ratevariation betas. This observation is consistent with the insignificant cash-flow-variation and discountrate-variation risk premia reported in Table 3. Even though discount-rate betas are significantly larger for small-cap stocks versus large-cap stocks, our findings suggest that the size effect is captured by covariation-risk betas. The insignificant risk premium of the discount-rate betas is also consistent with the results reported in prior research (e.g., Campbell and Vuolteenaho (2004)).
} 
pricing error $(\vartheta=0.033, p$-value $=0.56)$. The results for the ICAPM-CRD are qualitatively similar, indicating that the second-stage MGARCH estimation does not substantially influence the ability of these models to describe the cross section of portfolio returns. The only notable difference between the ICAPM-CRD and ICAPM-CRD-MGARCH is in their implied risk-aversion parameter, which is 24.58 for the former and 9.76 for the latter. As discussed in Section V.A, this is because the second-moment shocks are not persistent in the ICAPM-CRD but are persistent in the ICAPM-CRD-MGARCH, which enables the latter model to fit the data with a smaller risk-aversion parameter. Economically, this result suggests that the contemporaneous effects of double-whammy shocks and their long-term effects on future macroeconomic uncertainty are both important in explaining the returns on equity portfolios in our sample.

So far, we have compared the proposed nonlinear ICAPM to other theoretically motivated models. As a supplemental analysis, we compare the performance of the nonlinear ICAPM with two empirical models: the 4-factor Fama-FrenchCarhart model (Fama and French (1993), Carhart (1997)) and the 5-factor FamaFrench (2015) model. The adjusted $R^{2}$ of the 4-factor model is 0.71 ( $p$-value $=$ 0.01 ), and the model pricing error is 0.052 ( $p$-value $<0.01)$. The adjusted $R^{2}$ of the 5-factor model is 0.62 ( $p$-value $=0.09)$, and the model pricing error is 0.076 ( $p$-value $<0.01)$. Given these results, we consider the performance of the nonlinear ICAPM model to be at least comparable to the performance of these two empirical asset pricing models.

Lewellen et al. (2010) show that a model with high $R^{2}$ can still be misspecified if the estimate of the model intercept lies outside the range of plausible values predicted by economic theory. Our regressions use average monthly excess returns over the Treasury bill yield, so the intercepts reflect the average monthly risk premium of a zero-beta asset relative to the Treasury bill yield. If a zero-beta asset is assumed to be the Treasury bill, then significant intercept of the model reflects the "average" degree of model misspecification. For both the ICAPM-CRD and ICAPM-CRD-MGARCH, the estimated intercepts are not significant (largest estimate $=0.004, p$-value $=0.42$ ). In contrast, for most of the other models under consideration, the estimates of the intercepts are positive and significant (smallest estimate $=0.006, p$-value $=0.05$ ). Annualized, these estimates range from 7.2\% (Fama-French-Carhart model) to 15.6\% (2-beta ICAPM) above the Treasury bill yield. These magnitudes are too large to be reasonably attributed to factors such as the convenience yield provided to investors by Treasury bills or differences in borrowing versus lending rates (Lewellen et al. (2010), Krishnamurthy and Vissing-Jorgensen (2012)). Collectively, these findings provide further support for the proposed nonlinear ICAPM.

To summarize, the results reported in Panel A of Table 3 suggest that the proposed nonlinear ICAPM performs well in explaining the cross-sectional variation in the average returns of portfolios sorted by size, book-to-market ratio, past performance (momentum), investment, and profitability characteristics. The ability of the proposed nonlinear ICAPM to explain the momentum effect in our sample is particularly interesting because the momentum poses a particular challenge for asset pricing models (Lewellen et al. (2010)). Our findings provide a potential risk-based explanation for the momentum effect and are consistent with the 
results reported in Table 3, which show that past winners have greater exposure to covariation risk (i.e., have higher covariation betas) compared with past losers.

\section{Sensitivity Tests}

To gauge the robustness of our results, we conduct several sensitivity tests. In the first test, we consider the possibility that the insignificant results for the cash-flow-variation and discount-rate-variation risk premia are potentially driven by multicollinearity between the betas in our model. To examine this issue, we estimate three reduced versions of the nonlinear ICAPM where each of the three reduced versions of the nonlinear ICAPM has three factors: cash-flow news, discount-rate news, and one of the three second-moment news terms. The results are reported in Panel B of Table 3, showing that covariation risk retains its positive and statistically significant risk premium $(p$-value $<0.01) .{ }^{16}$ The estimated risk premium for cash-flow-variation risk remains insignificant $(p$-value $=0.92)$, and so does the estimated risk premium for the discount-rate-variation risk ( $p$-value $=0.18$ ). Turning to the models' explanatory power, the adjusted $R^{2}$ of the model where only covariation risk is retained is $0.65(p$-value $=0.01)$, and the model is not rejected based on its pricing error. In contrast, the adjusted $R^{2}$ of the model where only the cash-flow-variation risk is retained is $0.02(p$-value $=0.96)$, and the adjusted $R^{2}$ of the model where only the discount-rate-variation risk is retained is 0.15 ( $p$-value $=0.78$ ); the pricing errors of both models are statistically significant. Overall, these results emphasize the importance of covariation risk in the cross section of expected stock returns.

In the second test, we examine the sensitivity of our results to an alternative approach of estimating cash-flows news. As discussed earlier, we follow the Campbell and Vuolteenaho (2004) method of backing out cash-flow news from the unexpected market returns and discount-rate news. Their approach has two important advantages: i) It does not require assumptions regarding the short-run dynamics of aggregate dividends, and ii) It captures cash-flow news in the way that is perceived by the market (as reflected in the unexpected market returns). However, Chen and Zhao (2009) raise concerns about using the Campbell and Vuolteenaho (2004) approach because an indirect estimate of $N_{c, t+1}=\omega_{r, t+1}+N_{d, t+1}$ may inherit the misspecification error of $N_{d, t+1}$.

To address this concern, we estimate cash-flow news directly, following Chen and Zhao ((2009), eq. 24). We add monthly real dividend growth rates as the last column to the VAR in equation (13). Using this VAR, which now includes 5 time series, we estimate a $5 \times 5$ companion matrix $\boldsymbol{\Gamma}$. We estimate the cash-flow news component as $N_{c, t+1}^{*}=\mathbf{e}_{c}^{\prime} \boldsymbol{\lambda}_{\mathbf{c}} \mathbf{u}_{t+1}$, where the matrix $\boldsymbol{\lambda}_{\mathbf{c}}=(\mathbf{I}-\rho \boldsymbol{\Gamma})^{-1}$ maps instantaneous state-variable shocks to the news components of unexpected dividend

\footnotetext{
${ }^{16}$ In this specification, the estimate of the risk premium of the discount-rate news is negative. A potential interpretation of this negative sign is that the correlation between volatility news and discount-rate news is large. Consequently, when the variation-risk betas are omitted from the regression, discount-rate news becomes a stronger proxy for volatility news, showing up as a negative risk premium in the asset pricing tests. This interpretation is consistent with the evidence given by Bansal et al. (2014), who find that the estimated correlation between volatility news and discount-rate news is high. Bansal et al. interpret this finding as being consistent with the intuition of the Bansal and Yaron (2004) model, in which a significant component of discount-rate news is driven by shocks to consumption volatility.
} 
growth, and $\mathbf{e}_{c}$ is a vector with 1 as the last element and 0 s as the remaining elements. The discount-rate-news component of the unexpected market return is estimated as $N_{d, t+1}=\mathbf{e}_{d}^{\prime} \boldsymbol{\lambda}_{\mathbf{d}} \mathbf{u}_{t+1}$, where the matrix $\boldsymbol{\lambda}_{\mathbf{d}}=\rho \boldsymbol{\Gamma}(\mathbf{I}-\rho \boldsymbol{\Gamma})^{-1}$ maps instantaneous state-variable shocks to the news components of unexpected excess returns, and $\mathbf{e}_{d}$ is a vector with 1 as the first element and 0 s as the remaining elements. The return decomposition error term is backed out as $e_{t+1}=\omega_{r, t+1}-N_{c, t+1}^{*}+N_{d, t+1}=$ $N_{c, t+1}-N_{c, t+1}^{*}$, measuring the difference between the indirect and direct estimates of news to cash flows. ${ }^{17,18}$

Having constructed the estimates of $N_{c, t+1}^{*}, N_{d, t+1}$, and $e_{t+1}$, we evaluate the robustness of our findings to VAR misspecification error using a set of nested models. Our first model includes cash-flow news, discount-rate news, and covariation risk betas. In our second model, we add the beta of the return decomposition error term. In our third model, we further include the betas of the cross-products of the error term with cash-flow news and discount-rate news. The results are reported in Panel B of Table 3. We find that the estimate of covariation risk premium remains positive and significant across all three model specifications (largest $p$-value $=0.018)$. The 3 -factor model that includes cash-flow news, discountrate news, and covariation risk betas has an adjusted $R^{2}$ of $0.63(p$-value $=0.02)$ and is not rejected based on its pricing error $(\vartheta=0.053, p$-value $=0.317)$. These findings suggest that our main conclusions regarding the importance of covariation risk are robust to potential VAR misspecifications. Adding the error-term beta has no material impact on model performance, and the estimate of the error-term risk premium is not significant. Interestingly enough, we find that adding crossproducts of the error term with cash-flow news and discount-rate news leads to some (although moderate) improvement in model $R^{2}$, suggesting that these crossproduct terms capture a potentially meaningful missing component. On the one hand, this could reflect errors in the return decomposition (e.g., due to deviations from rationality). On the other hand, this could also be due to estimation error in our direct measure of cash-flow news $\left(N_{c, t+1}^{*}\right)$. We note that either scenario does not affect our main conclusion that the covariation between cash-flow news and discount-rate news is an important determinant of the cross section of returns.

In the third test, we consider the possibility that our findings could be driven by the "weak-factor" effect. Bryzgalova (2015) notes that if one of the factors in the model has weak covariance with stock returns, such a factor could generate spuriously high significance levels of its own risk-premium estimates while crowding out the impact of the true sources of risk. In our context, if the covariation risk factor possesses weak-factor properties, this could potentially result in a significant covariation risk premium and insignificant cash-flow-variation and discount-rate-variation risk premia. To examine this issue, we reestimate our

\footnotetext{
${ }^{17}$ We thank Robert Dittmar (the referee) for suggesting this test.

${ }^{18}$ The unconditional correlation between cash-flow news and discount-rate news estimated using this approach is negative $(-0.33)$. This contrasts with the small positive correlation $(0.01)$ obtained using the Campbell and Vuolteenaho (2004) estimation approach. We note, however, that this change in sign does not impact our conclusions because our model does not have a prediction for the sign of this unconditional correlation. In fact, a negative correlation between cash-flow news and discount-rate news suggests that the double-whammy shock is more likely to be prevalent, even in relatively better times. We thank the referee for pointing this out.
} 
model using a penalized Fama-MacBeth (Pen-FM) regression approach (Bryzgalova (2015)). This approach modifies a standard Fama-MacBeth regression by introducing a penalty term that is inversely proportional to factor strength. Estimating our model using the Pen-FM approach (results available from the authors) has no material impact on our findings. Thus, we conclude that our results are unlikely to be driven by the weak-factor effect.

\section{Estimation of Risk Premia Using the Implied Cost of Equity}

In the previous section, we estimated risk premia using the cross section of realized portfolio returns. Although widely adopted in the prior literature, this method also has several limitations. First, a test of the asset pricing theory requires a measure of ex ante (i.e., expected) rates of return. However, the noise in realized returns makes it a poor proxy for expected returns; thus, using realized returns in asset pricing tests could obscure important economic relations (Elton (1999), Lee et al. (2009)). Second, using portfolios sorted based on previously documented pricing anomalies (e.g., size, book-to-market ratio, or momentum) could lead to a data-snooping bias (Lewellen (1999), Lewellen et al. (2010)). Hence, in this section, we supplement our analysis by estimating our model for a panel of individual stocks using the approach of the implied cost of equity.

In terms of research design, we estimate the expected rate of return on equity as a discount rate that is implied by market prices and analysts' earnings forecasts, using four models introduced by Claus and Thomas (2001), Ohlson and Juettner-Nauroth (2005), Gebhardt, Lee, and Swaminathan (2001), and Easton (2004), respectively. ${ }^{19}$ Because there is little consensus in the literature on which model performs best, we perform an additional test using the median estimate from the four models (Hail and Leuz (2009)). For each model, we compute the implied risk premium, $\mathrm{IRP}_{i, t}$, as the difference between the corresponding implied expected return for firm $i$ and year $t$ and the 10-year U.S. Treasury bond yield.

We use the following regression to estimate the risk premia:

$$
\begin{aligned}
\mathrm{IRP}_{i, t}= & g_{0}+g_{1} \hat{\beta}_{c, i, t}+g_{2} \hat{\beta}_{d, i, t}+g_{3} \hat{\beta}_{c c, i, t}+g_{4} \hat{\beta}_{d d, i, t}+g_{5} \hat{\beta}_{c d, i, t} \\
& +\sum_{j=1}^{J} \delta_{j} \mathrm{CONTROL}_{j, i, t}+\mathrm{IND}_{i}+\varepsilon_{i, t} .
\end{aligned}
$$

For each firm-year observation, we compute the estimates of the cash-flow beta, the discount-rate beta, and the betas of the three coskewness risk components using the previous 60 months of stock returns (with at least 24 monthly returns). Following prior research, we include size, book-to-market ratio, leverage, past stock performance, the volatility of operating cash flows, the number of analysts following the firm, share turnover, and growth in the 1- and 2-year analyst earnings forecasts as control variables (Gebhardt et al. (2001), Chen et al. (2011)).

\footnotetext{
${ }^{19}$ An alternative to using analysts' earnings forecasts as a proxy for expected earnings (the approach commonly used in previous studies) is to rely on earnings forecasts from cross-sectional regression analysis (Hou, van Dijk, and Zhang (2012)). However, Li and Mohanram (2014) show that the forecasts from the model of Hou et al. (2012) perform worse than those of a naïve random-walk model. Further, they show that the measures of implied cost of capital estimated using Hou et al.'s approach show anomalous correlations with known risk factors. Given Li and Mohanram's findings, we use analysts' forecasts in estimating the measures of implied cost of equity.
} 
The data used to compute all the variables are from the Institutional Brokers' Estimate System (IBES), Compustat, and CRSP databases. Following Gebhardt et al. (2001), we estimate equation (16) cross-sectionally by year with industry fixed effects (IND) and report the time-series mean for each slope estimate. The standard errors (in parentheses) are adjusted for serial correlation following Newey and West (1987). To mitigate the potential impact of outliers, we truncate IRP at the 1st and 99th percentiles. Because IBES starts its coverage in 1986, the sample period for this analysis is 1986-2010.

The results are reported in Table 4. The coefficient for the covariation risk beta is positive and significant for four out of five model specifications. The only exception is the Claus-Thomas (2001) model, where the coefficient for the covariation risk premium is positive but insignificant. ${ }^{20}$ The estimates of the cash-flow-variation and discount-rate-variation risk premia are insignificant in all model specifications. Collectively, the results reported in this section are consistent with the results of portfolio-level tests and thus confirm the robustness of our findings.

TABLE 4

Asset Pricing Tests Using the Implied Cost of Equity

In Table 4, we report the estimated risk premia using the approach of the implied cost of equity for the sample of U.S. firms over the period 1986-2010. The dependent variable $\operatorname{IRP}_{i, t}$ is the implied risk premium, computed as the difference between the implied cost of equity for firm $i$ in year $t$ and the yield on a 10-year U.S. Treasury bond. We compute the implied cost of equity using five specifications: that of Claus and Thomas (CT) (2001), that of Ohlson and Juettner-Nauroth (OJ) (2005), the modified PEG model of Easton (MPEG) (2004), that of Gebhardt et al. (GLS) (2001), and the median of estimates obtained from the four models. The models are estimated cross-sectionally by year with control variables and industry fixed effects based on 2-digit Standard Industrial Classification codes included in all the regressions. The control variables are firm size, the firm book-to-market ratio, leverage, price momentum, the volatility of operating cash flows, the number of analysts following the firm, share turnover, and growth in the 1- and 2-year analyst earnings forecasts. FamaMacBeth standard errors adjusted for serial correlation following Newey and West (1987) are reported in parentheses. *, ${ }^{* *}$, and ${ }^{* *}$ indicate significance at the $10 \%, 5 \%$, and $1 \%$ levels, respectively.

\begin{tabular}{|c|c|c|c|c|c|}
\hline & Median & GLS & OJ & MPEG & СT \\
\hline Model & 1 & 2 & 3 & 4 & 5 \\
\hline$\beta_{c}$ & $\begin{array}{l}0.016^{\star \star} \\
(0.006)\end{array}$ & $\begin{array}{l}0.008^{\star \star \star} \\
(0.003)\end{array}$ & $\begin{array}{l}0.017^{* \star *} \\
(0.006)\end{array}$ & $\begin{array}{l}0.016^{\star \star \star} \\
(0.006)\end{array}$ & $\begin{array}{l}0.009^{\star \star} \\
(0.004)\end{array}$ \\
\hline$\beta_{d}$ & $\begin{array}{l}0.005^{\star \star \star} \\
(0.001)\end{array}$ & $\begin{array}{c}0.0003 \\
(0.001)\end{array}$ & $\begin{array}{l}0.006^{* * *} \\
(0.001)\end{array}$ & $\begin{array}{l}0.006^{\star \star \star} \\
(0.001)\end{array}$ & $\begin{array}{l}0.008^{\star \star \star} \\
(0.002)\end{array}$ \\
\hline$\beta_{c c}$ & $\begin{array}{c}0.026 \\
(0.068)\end{array}$ & $\begin{array}{c}-0.024 \\
(0.022)\end{array}$ & $\begin{array}{c}0.044 \\
(0.080)\end{array}$ & $\begin{array}{c}0.018 \\
(0.075)\end{array}$ & $\begin{array}{r}-0.240 \\
(0.170)\end{array}$ \\
\hline$\beta_{d d}$ & $\begin{array}{c}-0.041 \\
(0.039)\end{array}$ & $\begin{array}{c}-0.002 \\
(0.015)\end{array}$ & $\begin{array}{c}-0.051 \\
(0.036)\end{array}$ & $\begin{array}{c}-0.045 \\
(0.039)\end{array}$ & $\begin{array}{c}-0.009 \\
(0.056)\end{array}$ \\
\hline$\beta_{c d}$ & $\begin{array}{l}0.186^{\star \star \star} \\
(0.053)\end{array}$ & $\begin{array}{l}0.095^{\star * *} \\
(0.026)\end{array}$ & $\begin{array}{l}0.187^{\star * *} \\
(0.059)\end{array}$ & $\begin{array}{l}0.201^{\star \star \star} \\
(0.062)\end{array}$ & $\begin{array}{c}0.079 \\
(0.111)\end{array}$ \\
\hline Implied market premium & 0.046 & 0.010 & 0.063 & 0.055 & 0.024 \\
\hline $\begin{array}{l}\text { Controls } \\
\text { Industry fixed effects }\end{array}$ & $\begin{array}{l}\text { Yes } \\
\text { Yes }\end{array}$ & $\begin{array}{l}\text { Yes } \\
\text { Yes }\end{array}$ & $\begin{array}{l}\text { Yes } \\
\text { Yes }\end{array}$ & $\begin{array}{l}\text { Yes } \\
\text { Yes }\end{array}$ & $\begin{array}{l}\text { Yes } \\
\text { Yes }\end{array}$ \\
\hline Average adjusted $R^{2}$ & 0.184 & 0.414 & 0.219 & 0.215 & 0.096 \\
\hline
\end{tabular}

\footnotetext{
${ }^{20}$ Notably, the overall explanatory power of the Claus-Thomas (2001) model is low relative to that of other models.
} 


\section{Conclusion}

We develop an intertemporal asset pricing model in which coskewness risk decomposes into three components: cash-flow variation, discount-rate variation, and the covariation between cash-flow news and discount-rate news. In our model, long-term investors are willing to pay a premium to hedge an increase in variation and to hedge a decrease in covariation, and the risk premium for any asset is determined by asset exposure to cash-flow news, discount-rate news, and the three components of coskewness risk.

We evaluate the performance of our model using a cross section of portfolio returns sorted by size, book-to-market ratio, past stock performance (momentum), investment, and profitability. Our model accounts for $68 \%$ of the return variation across equity portfolios for the modern U.S. sample period, and it is not rejected at conventional significance levels. We find that stocks with good past performance, on average, have greater exposure to covariation risk compared with stocks with poor past performance. Further, we find that small-cap stocks, on average, have greater exposure to covariation risk compared with large-cap stocks. Our results suggest that during times of decreasing covariation (which increases the marginal utility of investors in our model), small stocks tend to underperform large stocks, and past winners tend to underperform past losers. Overall, the empirical evidence we present highlights the importance of decomposing coskewness risk into the variation and covariation risk components. In particular, our results suggest that differential exposures to covariation risk help explain a sizable amount of crosssectional variation in the expected stock returns.

\section{Appendix A. Evaluating a Second-Order Approximation of the Epstein-Zin Pricing Kernel}

The nonlinear Epstein-Zin (1991) pricing kernel is often implemented using a linear approximation. In Appendix A, we evaluate the improvement using our proposed secondorder approximation. To do so, we compare the empirical cumulative distribution function (ECDF) of the Epstein-Zin (1991) pricing kernel to the ECDFs of its first- and secondorder approximations.

Our first step is to construct the ECDF of the "true" Epstein-Zin (1991) pricing kernel, to which we compare its first- and second-order approximations. To do so, we first estimate the time series of the pricing kernel realizations (equation (2)) using market returns and consumption growth data and an assumed set of preference parameters for $\gamma$ (the risk-aversion coefficient) and $\psi$ (the IES parameter). Next, we estimate the ECDF of the pricing kernel realizations and its confidence intervals using Kaplan and Meier's (1958) nonparametric procedure.

Our second step is to estimate the ECDFs of the first- and second-order approximations of the Epstein-Zin (1991) pricing kernel. Asset betas are often estimated with respect to the market return and consumption growth after deriving a functional form for log SDF. Clearly, log SDF is linear in these two variables. However, our goal is to evaluate the loss in accuracy resulting from replacing the SDF (not log SDF) with a linear combination of market returns and consumption growth in standard asset pricing tests. For this purpose, we calculate a linear (first-order) approximation of the pricing kernel as the predicted value of an ordinary least squares (OLS) regression of the pricing-kernel realizations on the market return and consumption growth realization. Similarly, we calculate the second-order 
(quadratic) approximation of the pricing kernel as the predicted value of an OLS regression of the pricing-kernel realizations on the market return, consumption growth, and their three second-order terms.

The results are reported in Figure A1, which shows the ECDF of the pricing kernel, its confidence interval, and the ECDFs of the first- and second-order approximations of the pricing kernel. The results show that the ECDF of the linear approximation deviates significantly from that of the true underlying pricing kernel. Further, these deviations are particularly pronounced in the tails of the distribution. In contrast, the second-order approximation of the pricing kernel tends to stay within the confidence boundaries, suggesting that a second-order expansion of the Epstein-Zin (1991) pricing kernel provides a reasonably accurate approximation.

\section{FIGURE A1}

\section{Epstein-Zin Pricing Kernel Approximations}

Figure A1 shows the empirical cumulative distribution of the Epstein-Zin (1991) pricing kernel and the pricing kernel's firstorder (linear) and second-order (quadratic) approximations. The Epstein-Zin pricing-kernel realizations are calculated using a risk-aversion coefficient of 2 , an intertemporal elasticity of substitution (IES) of 1.5, and data on market returns and consumption growth from July 1963 to Dec. 2010. LCB represents the lower confidence bound, and UCB represents the upper confidence bound.

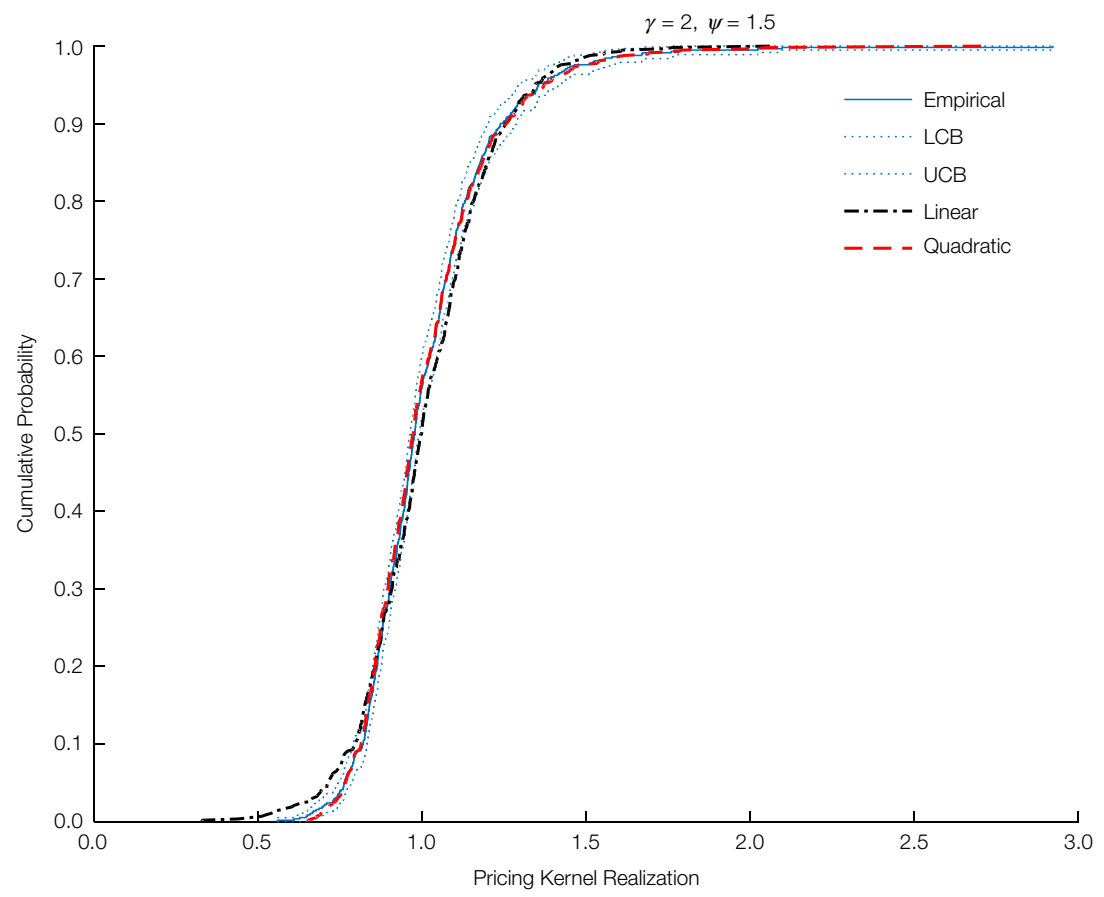

\section{Appendix B. Derivation of SDF for the ICAPM-CRD-MGARCH Model}

The assumed MGARCH process for cash-flow news and discount-rate news is as follows:

$$
\mathbf{H}_{t+s}=\mathbf{C}^{\prime} \mathbf{C}+\mathbf{A}^{\prime} \mathbf{N}_{t+s} \mathbf{N}_{t+s}^{\prime} \mathbf{A}+\mathbf{G}^{\prime} \mathbf{H}_{t+s-1} \mathbf{G},
$$


where $\mathbf{H}_{t}$ is the $2 \times 2$ conditional covariance matrix of $N_{c, t+1}$ and $N_{d, t+1} ; \mathbf{N}_{t}$ denotes a $2 \times 1$ vector of the news terms; and $\mathbf{C}, \mathbf{A}$, and $\mathbf{G}$ are $2 \times 2$ matrices of constants. This assumption is sufficiently general because it encompasses a variety of positive definite representations of the covariance matrix (Engle and Kroner (1995)). We further assume that the process is covariance stationary. The expression for the conditional volatility of cash-flow news implied by the MGARCH process defined in equation (B-1) is

$$
\begin{aligned}
h_{c c, t}= & c_{11}+a_{c c}^{2} N_{c, t}^{2}+2 a_{c c} a_{d c} N_{c, t} N_{d, t}+a_{d c}^{2} N_{d, t}^{2} \\
& +g_{c c}^{2} h_{c c, t-1}+2 g_{c c} g_{d c} h_{c d, t-1}+g_{d c}^{2} h_{d d, t-1},
\end{aligned}
$$

where $a_{x y}$ denotes an element of $\mathbf{A}$, the ARCH persistence matrix, and $g_{x y}$ denotes an element of $\mathbf{G}$, the GARCH persistence matrix. With this MGARCH process assumption in hand, we solve for a second-order approximation of $N_{p, t+1}: 21$

$$
\begin{aligned}
N_{p, t+1} & \approx\left(\mathrm{E}_{t+1}-\mathrm{E}_{t}\right) \sum_{j=1}^{\infty} \rho^{j}(1-\gamma)^{2} N_{c, t+1+j}^{2} \\
& \approx\left(\mathrm{E}_{t+1}-\mathrm{E}_{t}\right) \sum_{j=1}^{\infty} \rho^{j}(1-\gamma)^{2} h_{c c, t+1+j} \\
& \approx(1-\gamma)^{2} \chi\left\{a_{c c}^{2} N_{c c, t+1}+a_{d c}^{2} N_{d d, t+1}+2 a_{d c} a_{c c} N_{c d, t+1}\right\},
\end{aligned}
$$

where $N_{c c, t+1}, N_{d d, t+1}$, and $N_{c d, t+1}$ are news about the second-order terms of $N_{c, t+1}$ and $N_{d, t+1}$, given by $N_{c, t+1}^{2}-h_{c c, t}, N_{d, t+1}^{2}-h_{d d, t}$, and $N_{c, t+1} N_{d, t+1}-h_{c d, t}$, respectively, and $\chi$ is a scale parameter that captures the link between news about long-run aggregate volatility and the variance of the next period's cash-flow news $\left(h_{c c, t+1}\right)$. The MGARCH parameters map the impact of these 1-period realizations on the long-run aggregate volatility forecasts.

To derive an expression for $\omega_{v, t+1}$ in terms of $N_{c, t+1}$ and $N_{d, t+1}$, we follow the development in the previous section and eliminate third- and higher-order terms of $N_{c, t+1}$ and $N_{d, t+1}$ from its expression. Note that according to equation (B-3), $N_{p, t+1}$ is a second-order function of $N_{c, t+1}$ and $N_{d, t+1}$. Therefore, the third- and higher-order terms of $N_{p, t+1}$ do not contribute to the second-order approximation of $\omega_{v, t+1}=\left[\left\{(\theta / \psi) \omega_{c, t+1}+(1-\theta) \omega_{r, t+1}\right\}^{2}-h_{m, t}\right]$. This result further implies that the expression for $\omega_{v, t+1}$ in terms of first- and second-order terms of $N_{c, t+1}$ and $N_{d, t+1}$ (after eliminating higher-order terms) is given by

$$
\begin{aligned}
\omega_{v, t+1} & \approx\left(\mathrm{E}_{t+1}-\mathrm{E}_{t}\right)\left(-\gamma N_{c, t+1}+N_{d, t+1}\right)^{2} \\
& =\gamma^{2} N_{c c, t+1}+N_{d d, t+1}-2 \gamma N_{c d, t+1} .
\end{aligned}
$$

Having expressed precautionary-savings news $\left(N_{p, t+1}\right)$ and the shocks to the square of $\log \operatorname{SDF}\left(\omega_{v, t+1}\right)$ in terms of the cash-flow news and discount-rate news, we plug the resulting expressions from equations (B-3) and (B-4) into equation (7) to obtain the expression for our SDF in equation (11).

\footnotetext{
${ }^{21}$ Note that the expression for $N_{p, t+1}$ in equation (6) depends on the expectation of the square of future cash-flow news and the square of future precautionary-savings news. Therefore, its square will be of order 2 or more in cash-flow news. Therefore, the second-order approximation of equation (6) only depends on news about the long-run variance of cash-flow news. The other two components (longrun variance of precautionary-savings news and long-run covariance between precautionary-savings news and cash-flow news) are of order 3 or more. This implies that under our assumptions, the other two components related to future precautionary-savings news are of order 3 or more. Consequently, for analytical tractability, we ignore these terms.
} 


\section{References}

Bali, T. G.; H. Mo; and Y. Tang. "The Role of Autoregressive Conditional Skewness and Kurtosis in the Estimation of Conditional VaR." Journal of Banking and Finance, 32 (2008), 269-282.

Bansal, R.; D. Kiku; I. Shaliastovich; and A. Yaron. "Volatility, the Macroeconomy and Asset Prices." Journal of Finance, 69 (2014), 2471-2511.

Bansal, R., and A. Yaron. "Risks for the Long Run: A Potential Resolution of Asset Pricing Puzzles." Journal of Finance, 59 (2004), 1481-1509.

Barone-Adesi, G.; P. Gagliardini; and G. Urga. "Testing Asset Pricing Models with Coskewness." Journal of Business and Economic Statistics, 22 (2004), 474-485.

Bloom, N. "Fluctuations in Uncertainty." Journal of Economic Perspectives, 28 (2014), 153-175.

Bryzgalova, S. "Spurious Factors in Linear Asset Pricing Models." Working Paper, Stanford University (2015).

Campbell, J. Y. "Intertemporal Asset Pricing without Consumption Data." American Economic Review, 83 (1993), 487-512.

Campbell, J. Y. "Consumption-Based Asset Pricing." In Handbook of the Economics of Finance, G. M. Constantinides, M. Harris, and R. Stulz, eds. Amsterdam: Elsevier (2003).

Campbell, J. Y.; Y. L. Chan; and L. M. Viceira. "A Multivariate Model of Strategic Asset Allocation." Journal of Financial Economics, 67 (2003), 41-80.

Campbell, J. Y.; S. Giglio; C. Polk; and R. Turley. "An Intertemporal CAPM with Stochastic Volatility." Journal of Financial Economics, 128 (2018), 207-233.

Campbell, J. Y., and T. Vuolteenaho. "Bad Beta, Good Beta." American Economic Review, 94 (2004), 1249-1275.

Carhart, M. M. "On Persistence in Mutual Fund Performance.” Journal of Finance, 52 (1997), 57-82.

Chen, K. C. W.; Z. Chen; and K. C. J. Wei. "Agency Costs of Free Cash Flows and the Effect of Shareholder Rights on the Implied Cost of Capital." Journal of Financial and Quantitative Analysis, 46 (2011), 171-207.

Chen, L., and X. Zhao. "Return Decomposition.” Review of Financial Studies, 22 (2009), 5213-5249.

Chen, Y.; T. F. Cosimano; and A. A. Himonas. "On Formulating and Solving Portfolio Decision and Asset Pricing Problems." In Handbook of Computational Economics, Vol. 3, K. L. Judd and K. Schmedders, eds. Amsterdam, Netherlands: Elsevier, North-Holland (2013).

Claus, J., and J. Thomas. "Equity Premia as Low as Three Percent? Evidence from Analysts' Earnings Forecasts for Domestic and International Stock Markets.” Journal of Finance, 56 (2001), 1629-1666.

Cochrane, J. H. "Presidential Address: Discount Rates.” Journal of Finance, 66 (2011), 1047-1108.

Dittmar, R. F. "Nonlinear Pricing Kernels, Kurtosis Preference, and Evidence from the Cross Section of Equity Returns.” Journal of Finance, 57 (2002), 369-403.

Easton, P. "PE Ratios, PEG Ratios, and Estimating the Implied Expected Rate of Return on Equity Capital." Accounting Review, 79 (2004), 73-96.

Elton, E. J. "Expected Return, Realized Return, and Asset Pricing Tests." Journal of Finance, 54 (1999), 1199-1220.

Engle, R. F., and K. F. Kroner. "Multivariate Simultaneous Generalized ARCH.” Econometric Theory, 11 (1995), 122-150.

Epstein, L., and S. E. Zin. "Substitution, Risk Aversion, and the Temporal Behavior of Consumption and Asset Returns: A Theoretical Framework." Econometrica, 7 (1989), 937-969.

Epstein, L. G., and S. E. Zin. "Substitution, Risk Aversion, and the Temporal Behavior of Consumption and Asset Returns: An Empirical Analysis.” Journal of Political Economy, 99 (1991), 263-286.

Fama, E. F., and K. R. French. "Common Risk Factors in the Returns on Stocks and Bonds." Journal of Financial Economics, 33 (1993), 3-56.

Fama, E. F., and K. R. French. “A Five-Factor Asset Pricing Model.” Journal of Financial Economics, 116 (2015), 1-22.

Fama, E. F., and J. D. MacBeth. "Risk, Return, and Equilibrium: Empirical Tests." Journal of Political Economy, 81 (1973), 607-636.

Foote, C.; E. Hurst; and J. Leahy. "Testing the (S,s) Model." American Economic Review, 90 (2000), $116-119$.

Gebhardt, W. R.; C. M. C. Lee; and B. Swaminathan. "Toward an Implied Cost of Capital." Journal of Accounting Research, 39 (2001), 135-176.

Hahn, J., and H. Lee. "Yield Spreads as Alternative Risk Factors for Size and Book-to-Market." Journal of Financial and Quantitative Analysis, 41 (2006), 245-269.

Hail, L., and C. Leuz. "Cost of Equity Effects and Changes in Growth Expectations around U.S. Cross-Listings.” Journal of Financial Economics, 93 (2009), 428-454. 
Harrison, J. M., and D. M. Kreps. "Martingales and Arbitrage in Multiperiod Securities Markets." Journal of Economic Theory, 20 (1979), 381-408.

Harvey, C. R., and A. Siddique. "Autoregressive Conditional Skewness." Journal of Financial and Quantitative Analysis, 34 (1999), 465-487.

Harvey, C. R., and A. Siddique. "Conditional Skewness in Asset Pricing Tests.” Journal of Finance, 55 (2000), 1963-1295.

Hodrick, R. J., and X. Zhang. "Evaluating the Specification Errors of Asset Pricing Models." Journal of Financial Economics, 62 (2001), 327-376.

Hou, K.; M. van Dijk; and Y. Zhang. "The Implied Cost of Capital: A New Approach.” Journal of Accounting and Economics, 53 (2012), 504-526.

Jegadeesh, N., and S. Titman. "Returns to Buying Winners and Selling Losers: Implications for Stock Market Efficiency." Journal of Finance, 48 (1993), 65-91.

Jegadeesh, N., and S. Titman. "Momentum.” In Advances in Behavioral Finance, Vol. II, R. M. Thaler, ed. Princeton, NJ: Princeton University Press (2005).

Kaplan, E. L., and P. Meier. "Nonparametric Estimation from Incomplete Observations." Journal of the American Statistical Association, 53 (1958), 457-481.

Kimball, M. S. "Precautionary Saving in the Small and in the Large." Econometrica, 58 (1990), 53-73.

Kraus, A., and R. H. Litzenberger. "Skewness Preference and Valuation of Risky Assets." Journal of Finance, 31 (1976), 1085-1100.

Krishnamurthy, A., and A. Vissing-Jorgensen. "The Aggregate Demand for Treasury Debt.” Journal of Political Economy, 120 (2012), 233-267.

Lee, C.; D. Ng; and B. Swaminathan. "Testing International Asset Pricing Models Using Implied Costs of Capital." Journal of Financial and Quantitative Analysis, 44 (2009), 307-355.

Lewellen, J. "The Time-Series Relations among Expected Return, Risk, and Book-to-Market.” Journal of Financial Economics, 54 (1999), 5-43.

Lewellen, J.; S. Nagel; and J. Shanken. "A Skeptical Appraisal of Asset Pricing Tests." Journal of Financial Economics, 96 (2010), 175-194.

Li, K. K., and P. Mohanram. "Evaluating Cross-Sectional Forecasting Models for Implied Cost of Capital." Review of Accounting Studies, 19 (2014), 1152-1185.

Lim, K.-G. "A New Test of the Three-Moment Capital Asset Pricing Model." Journal of Financial and Quantitative Analysis, 24 (1989), 205-216.

Lintner, J. "The Valuation of Risky Assets and the Selection of Risky Investments in Stock Portfolios and Capital Budgets." Review of Economics and Statistics, 47 (1965), 13-37.

Merton, R. C. “An Intertemporal Capital Asset Pricing Model.” Econometrica, 41 (1973), 867-887.

Newey, W. K., and K. D. West. "A Simple, Positive Semi-Definite, Heteroskedasticity and Autocorrelation Consistent Covariance Matrix.” Econometrica, 55 (1987), 703-708.

Novy-Marx, R. "The Other Side of Value: The Gross Profitability Premium." Journal of Financial Economics, 108 (2013), 1-28.

Ohlson, J. A., and B. E. Juettner-Nauroth. "Expected EPS and EPS Growth as Determinants of Value." Review of Accounting Studies, 10 (2005), 349-365.

Sharpe, W. F. "Capital Asset Prices: A Theory of Market Equilibrium under Conditions of Risk." Journal of Finance, 19 (1964), 425-442. 